\title{
Geomagnetic Transfer Functions in Japan Obtained by First Order Geomagnetic Survey
}

\author{
Satoshi FUJWARA ${ }^{1}$ and Hiroaki ToH ${ }^{2}$ \\ ${ }^{1}$ Geographical Survey Institute, Tsukuba 305, Japan \\ ${ }^{2}$ Ocean Research Institute, University of Tokyo, Nakano-ku, Tokyo 164, Japan
}

(Received September 13, 1995; Revised April 15, 1996; Accepted April 26, 1996)

\begin{abstract}
Repeated measurements of the Earth's time varying magnetic field have been made across Japan by the Geographical Survey Institute. Such measurements are known as a first order geomagnetic survey. There are 105 geomagnetic stations located uniformly across the whole of Japan. Since 1987, triaxial fluxgate magnetometers have been used to obtain one-minute data at almost all stations. From the geomagnetic data, transfer functions were determined for each station. Traditional vertical field transfer functions of wide period range (from $4 \mathrm{~min}$ to $128 \mathrm{~min}$ ) were obtained, making use of the interstation method. Additionally, we calculated transfer functions for the horizontal field. The distribution of the transfer functions can be used to form a reference map of geomagnetic induction in Japan. Moreover, the distribution of the horizontal transfer functions in Japan has been examined for the first time. After eliminating the effect of the sea water using thin-sheet models, large regional anomalies are found to remain. These anomalies are diagnostic of the resistivity structure and show patterns of current channeling in Japan.
\end{abstract}

\section{Introduction}

Since the 1950's it has been known that the vertical components of geomagnetic variations at periods shorter than several hours differ in amplitude and phase significantly from one place to another. Such differences can be used to map conductivity anomalies (CA) and have been studied by many scientists in Japan (e.g. Rikitake, 1966). For example, large CA in central Japan and northeastern Japan have been discovered. Rikitake (1969) accounted for such anomalies by assuming an undulation of a mantle conducting layer, as it was thought that these $\mathrm{CA}$ had a close relation to the resistivity structure of the upper mantle.

It is well known that an empirical linear relation exists among the three components of short-period geomagnetic variations (e.g. "Bay type" variations):

$$
\Delta Z=A \cdot \Delta X+B \cdot \Delta Y
$$

where $\Delta X, \Delta Y$ and $\Delta Z$ are geographic north, east and vertical components of geomagnetic variations, respectively, and these are mathematically complex Fourier components. This relation is interpreted as a linear system that has two inputs of $\Delta X$ and $\Delta Y$, and an output $\Delta Z$. The coefficients $A$ and $B$ are constants which are specific to a given station and are frequency-dependent complex transfer functions. Transfer functions have been extensively studied in Japan (observed induction arrows were compiled by Handa $e t$ al. (1992) and Bapat et al. (1993)), but a nation-wide survey has not been previously attempted.

The study of the transfer functions has been usually made using the anomalies of the vertical field component. Additionally, anomalies of the horizontal field component were also observed at many stations. Nishida (1981) found that the amplitudes of horizontal fields at selected stations were 1.8 times as large as those at a reference station. However, the study of the horizontal anomalies has not been extensively made because there are two difficulties; firstly in synchronizing the clocks at two stations, and secondly in defining a reference "normal field". 
Anomalies of the horizontal component correspond to shallow low resistivity structure, as they attenuate more rapidly than the vertical anomalous component with increasing distance from the structure of interest (e.g. Rikitake and Honkura, 1985). In other words, the anomalous horizontal fields are more localized in comparison with the anomalous vertical fields, and therefore, the study of the anomalous horizontal fields may provide additional information on the resistivity structure of the Earth. This study is the first attempt to determine the distribution of the horizontal anomalies over the whole of Japan.

\section{Data}

Ground geomagnetic surveys in Japan have been carried out by the Geographical Survey Institute since 1949 in order to investigate the geographical distribution of the geomagnetic secular variation (Geographical Survey Institute, 1995). Such measurements are known as a first order geomagnetic survey. There are 105 geomagnetic stations which uniformly cover the whole of Japan (Fig. 1 and Table 1). Observations are carried out every 2 or 5 years.

Since 1987, triaxial fluxgate magnetometers have been used to collect one-minute data at almost all the stations (Otaki and Tsukahara, 1990). This instrument has a temperature dependence of $0.2 \mathrm{nT} /{ }^{\circ} \mathrm{C}$ for the sensor and $0.1 \mathrm{nT} /{ }^{\circ} \mathrm{C}$ for the control unit, with a stability of $0.1 \mathrm{nT} /$ day and resolution of $0.1 \mathrm{nT}$. The sensor is mounted on gimbals so that $Z$ is aligned with the vertical direction by gravity, and the sensor case is buried to reduces the effects of ambient temperature changes. Timing accuracy is within 3 seconds, so

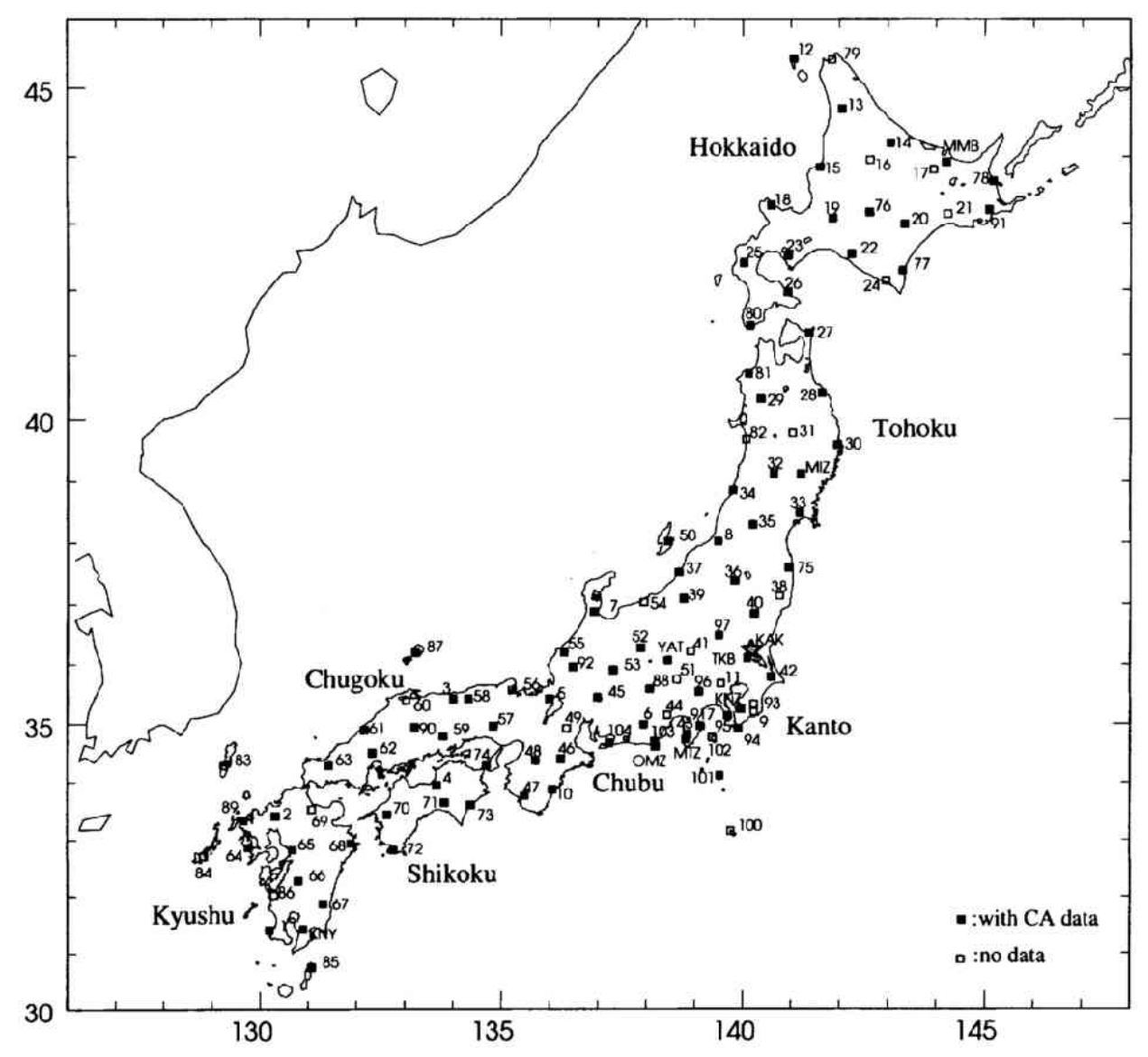

Fig. 1. Locations of the first order geomagnetic stations and the geomagnetic observatories. 
Table 1. Names and locations of the first order geomagnetic stations and the observatories.

\begin{tabular}{|c|c|c|c|c|c|c|}
\hline \multirow[t]{2}{*}{ Vum } & \multirow[t]{2}{*}{ lame } & \multirow{2}{*}{$\begin{array}{c}\text { Japanese } \\
\text { name }\end{array}$} & \multicolumn{2}{|c|}{ Latitude } & \multicolumn{2}{|c|}{ Longi tude } \\
\hline & & & & min & deg & min \\
\hline 1 & KAGOSHIMA & & 31 & 23.7 & 130 & 10.8 \\
\hline 2 & SEBURIYAMA & & 33 & 25.0 & 130 & 18.5 \\
\hline 3 & KURAYOSHI & 吉 & 35 & 24.6 & 133 & 59.8 \\
\hline 4 & KAWANOE & & 33 & 56.6 & 133 & 39.3 \\
\hline 5 & IMAZU & & 35 & 24.7 & 135 & 59.4 \\
\hline 6 & HAMAMATSU & 松 & 34 & 59.3 & 137 & 56.5 \\
\hline 7 & HIMI & & 36 & 52.1 & 136 & 55.2 \\
\hline 8 & SHIBATA & & 38 & 1.3 & 139 & 28.9 \\
\hline 9 & KATSUIRA & 浦 & 35 & 11.9 & 140 & 14.1 \\
\hline 10 & KUMANO & & 33 & 52.4 & 136 & 3. 1 \\
\hline 11 & MITAKA & & 35 & 40.4 & 139 & 33.0 \\
\hline 12 & REBUNTOU & & 45 & 25.4 & 141 & 2. 7 \\
\hline 13 & NAKAGAWA & 中 & 44 & 42.0 & 142 & 2. 3 \\
\hline 14 & TAKINOUE & 滝 & 44 & 12.0 & 143 & 2.5 \\
\hline 15 & RUMO1 & 萌 & 43 & 50.4 & 141 & 35.5 \\
\hline 16 & ASAHIKAWA & ภiा & 43 & 57.1 & 142 & 37.3 \\
\hline 17 & KITAMI & 見 & 43 & 47.8 & 143 & 56.2 \\
\hline 18 & FURUBIRA & & 43 & 16. 2 & 140 & 34. 7 \\
\hline 19 & IWAMIZAWA & 岩見沢 & 43 & 4.6 & 141 & 51.2 \\
\hline 20 & OBIHIRO & 広 & 42 & 59.2 & 143 & 20.1 \\
\hline 21 & KUISHIRO & 路 & 43 & 8.3 & 144 & 13.4 \\
\hline 22 & MONBETSU & 別 & 42 & 31.8 & 142 & 13.9 \\
\hline 23 & DATE & 達 & 42 & 30.9 & 140 & 55.8 \\
\hline 24 & SAMANI & 以 & 42 & 8.0 & 142 & 57.1 \\
\hline 25 & IMAKANE & 金 & 42 & 24.2 & 140 & \\
\hline 26 & KAYABE & 部 & 41 & 57.4 & 140 & 55.6 \\
\hline 27 & SHIMOKITA & 北 & 41 & 19.9 & 141 & 22.3 \\
\hline 28 & HACHINOHE & 声 & 40 & 23.7 & 141 & 37.6 \\
\hline 29 & OODATE & 舘 & 40 & 18.4 & 140 & 22.3 \\
\hline 30 & MIYAKO & 占 & 39 & 34.5 & 141 & 57.5 \\
\hline 31 & MORIOKA & 岡 & 39 & 46.3 & 141 & 2.0 \\
\hline 32 & YOKOTE & 手 & 39 & 7.2 & 140 & 38.6 \\
\hline 33 & ISHINOMAKI & 巻 & 38 & 29.3 & 141 & 11. 1 \\
\hline 34 & SAKATA & 田 & 38 & 50.8 & 139 & 47.6 \\
\hline 35 & YAMAGATA & 形 & 38 & 18.0 & 140 & 13.1 \\
\hline 36 & WAKAMATSU & 松 & 37 & 22.6 & 139 & 49.5 \\
\hline 37 & IZLMOZAKI & 出雲崎 & 37 & 30.7 & 138 & 39.8 \\
\hline 38 & IWAKI & いわき & 37 & 7. 6 & 140 & 46.0 \\
\hline 39 & TOOKAMACHI & 十百町 & 37 & 5.2 & 138 & 46.3 \\
\hline 40 & UTSUNOMIYA & & 36 & 50.3 & 140 & 14.5 \\
\hline 41 & TOMIOKA & 岡 & 36 & 12.5 & 138 & 55.2 \\
\hline 42 & CHOUSHI & 7 & 35 & 47.4 & 140 & 35.2 \\
\hline 43 & NISHIIZU & 西伊豆 & 34 & 49.3 & 138 & 50.8 \\
\hline 44 & SHIMIZU & 水 & 35 & 9.0 & 138 & 25.5 \\
\hline 45 & INEYAMA & 山 & 35 & 26.3 & 136 & 58.8 \\
\hline 46 & MIE & 重 & 34 & 24.2 & 136 & 13.4 \\
\hline 47 & TANABE & 辺 & 33 & 45.6 & 135 & 28. 3 \\
\hline 48 & GOJOU & 条 & 34 & 22.3 & 135 & 42.2 \\
\hline 49 & KOLGGA & 賀 & 34 & 54.8 & 136 & 21.0 \\
\hline 50 & RYOUZU & 津 & 38 & 9 & 138 & 27.2 \\
\hline 51 & KOLFU & 府 & 35 & 44.6 & 138 & 37.7 \\
\hline 52 & MATSUMOTO & 本 & 36 & 15.9 & 137 & 52.9 \\
\hline 53 & TAKAYAMA & 山 & 35 & 54.0 & 137 & 19. 2 \\
\hline 54 & ITOIGAWA & 夈魚川 & 37 & 1.4 & 137 & 56.7 \\
\hline 55 & FUKUII & 井 & 36 & 11.7 & 136 & 18. 1 \\
\hline 56 & MIYAZU & 津 & 35 & 33.7 & 135 & 13.4 \\
\hline 57 & HIMEJI & 路 & 34 & 57.6 & 134 & 50.0 \\
\hline 58 & TOTTORI & 鳥 取 & 35 & 24.8 & 134 & 18.7 \\
\hline 59 & OKAYAMA & 山 & 34 & 46.7 & 133 & 47.4 \\
\hline
\end{tabular}

\begin{tabular}{|c|c|c|c|c|c|c|}
\hline \multirow{3}{*}{$\frac{\text { Num }}{60}$} & \multirow{3}{*}{$\begin{array}{l}\text { Name } \\
\text { MATSUE }\end{array}$} & \multirow{2}{*}{$\begin{array}{l}\text { Japanese } \\
\text { name }\end{array}$} & \multicolumn{2}{|c|}{ Latitude } & \multicolumn{2}{|c|}{ Long i tude } \\
\hline & & & deg & min & dog & win \\
\hline & & 松 & 35 & 22.9 & 133 & 1.1 \\
\hline & HAMADA & & & & & 10. \\
\hline & HIM & 度 & 34 & & 132 & 19. \\
\hline & & II & 34 & & & $25 .:$ \\
\hline & $\mathrm{N}$ & & 32 & 51.3 & 129 & 45.1 \\
\hline & & 熊 & 32 & 49.0 & 130 & 39.6 \\
\hline & & 人 & 32 & 1 & & 46.6 \\
\hline & MIYAZ & 菅 & 31 & 51.6 & 131 & 176 \\
\hline & & 佐 & 32 & 55.7 & 13 & $52 . .5$ \\
\hline & SU & 中 & 33 & 31.5 & 131 & 3.7 \\
\hline & & & 33 & & 132 & 38.2 \\
\hline & & th & 33 & & 13 & 48.8 \\
\hline 7 & JRA & $\mathrm{T}$ & 32 & 48.4 & $1: 32$ & 45.6 \\
\hline 7 & & 大 & 33 & & & 22.0 \\
\hline 7. & & & & & & 40. \\
\hline 75 & МАCHI & & 37 & 35 & & 57.2 \\
\hline & & 练 & 43 & & & 36. \\
\hline 7 & & & 42 & & 1. & 17.4 \\
\hline 78 & TSU & 標 & 43 & & 14 & 10.2 \\
\hline & & 踓 & 45 & & & 49.8 \\
\hline 8 & & & 41 & & & 8.6 \\
\hline 8. & WARA & 们原 & 40 & 41. 8 & & 6.9 \\
\hline & & 田 & 3 & & & 4.3 \\
\hline & & & 3 & & & 14. 4 \\
\hline 8 & & & 32 & & & 49. 4 \\
\hline 8 & $\mathrm{~T}$ & & 30 & 43.9 & & 4.1 \\
\hline & & & 32 & 1. 2 & & 16.6 \\
\hline & & & 36 & 11.5 & $1:$ & 13.5 \\
\hline & & 丒 & 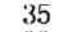 & & & 3.9 \\
\hline 8 & & 1: & 33 & & & 38.6 \\
\hline & & 城 & & & & 12. \\
\hline & & & & & & 4.5 \\
\hline 9 & & & 3 & 5 & & 29.0 \\
\hline & & 葉 & & & & 13.6 \\
\hline & & 館 & 3 & 5 & 1 & 53.9 \\
\hline & & & 3 & 3 & $1 ?$ & 40.7 \\
\hline & & 爷 & & & & 53 \\
\hline & & & 3 & 28 & & 29.9 \\
\hline & IIM & & 2 & & & 13.1 \\
\hline & & sith & & & & 14. \\
\hline 0 & MA & & 3 & & & 44 \\
\hline 10 & IIMA & 島 & 34 & 0 & 1 & 30.7 \\
\hline & IMA & & 34 & 46 & & 21.6 \\
\hline & & & $\therefore$ & 41 & & 9 \\
\hline & & & 34 & & & 13.4 \\
\hline & & 石 & & & & 11.5 \\
\hline & & & & & 13 & 6 \\
\hline & & & & & & 7. 5 \\
\hline & & & & & & 2. \\
\hline & & & 36 & & & 5.5 \\
\hline & & & & & & 4 \\
\hline & & & & & & 52. \\
\hline & M & 女満別 & 43 & 54.5 & 144 & 11.6 \\
\hline & & & & & & \\
\hline & & Ш & & & & 11 \\
\hline YA & Yatsugatake & 八ケ岳 & 36 & 4. 1 & 138 & 26.6 \\
\hline
\end{tabular}

we can get simultaneous data with the permanent geomagnetic observatories.

The observations and analyses conducted in this study have the following features:

(a) First order geomagnetic stations are uniformly distributed over the whole of Japan.

(b) Instruments of observations and the method of analyses are the same for each first order geomagnetic station. 
(c) Since the absolute declinations are precisely measured at all station, induction arrows are relative to the true geographical coordinates.

(d) As we regularly re-observe at the first order geomagnetic stations every 2 or 5 years, the time variations of the transfer functions can be obtained.

We have also used data from permanent geomagnetic observatories. The Geographical Survey Institute operates geomagnetic observatories at Mizusawa (MIZ), Kanozan (KNZ) and Tsukuba (TKB) (see Fig. 1). In addition, we used data from other observatories, namely Kakioka (KAK), Memanbetsu (MMB), Kanoya (KNY), Matsuzaki (MTZ) and Omaezaki(OMZ), which are operated by the Japan Meteorological Agency, and Yatsugatake (YAT), which is operated by the Earthquake Research Institute, the University of Tokyo. These observations are carried out in magnetically quiet variation huts at each observatory, in which three geomagnetic components $(H, D$ and $Z$ ) were measured digitally every minute, with a least count of $0.1 \mathrm{nT}$.

\section{Data Analyses}

\subsection{Transfer function}

Vertical field transfer functions can be derived simply from Eq. (1). In this study, we refine Eq. (1) by making use of data from different observation sites. This approach is known as the interstation method. Using the interstation method, we can also calculate horizontal transfer functions.

Geomagnetic variations observed at a field station can be separated into normal and anomalous parts. The normal part is composed of an external field, and an internal field that arises from current flowing in "normal" earth structure. On the other hand, the anomalous part is composed only of an internal field that arises from current flowing in "anomalous" earth structure (Beamish, 1982).

The interstation transfer functions are written using these normal and anomalous parts:

$$
\left(\begin{array}{l}
\Delta X_{s} \\
\Delta Y_{s} \\
\Delta Z_{s}
\end{array}\right)=\left(\begin{array}{c}
\Delta X_{n} \\
\Delta Y_{n} \\
\Delta Z_{n}
\end{array}\right)+\left(\begin{array}{c}
\Delta X_{a} \\
\Delta Y_{a} \\
\Delta Z_{a}
\end{array}\right)=\left(\begin{array}{c}
\Delta X_{n} \\
\Delta Y_{n} \\
\Delta Z_{n}
\end{array}\right)+\left(\begin{array}{ccc}
C & D & G \\
E & F & H \\
A & B & I
\end{array}\right) \cdot\left(\begin{array}{c}
\Delta X_{n} \\
\Delta Y_{n} \\
\Delta Z_{n}
\end{array}\right)+\left(\begin{array}{c}
\delta X \\
\delta Y \\
\delta Z
\end{array}\right)
$$

where $A, B, C, D, E, F, G, H$ and $I$ are interstation transfer functions and $\delta X, \delta Y$ and $\delta Z$ are uncorrelated parts of the corresponding components (Schmucker, 1970), including errors. $\Delta X_{s}, \Delta Y_{s}$ and $\Delta Z_{s}$ are the three components of geomagnetic variations of an observation site; $\Delta X_{a}, \Delta Y_{a}$ and $\Delta Z_{a}$ are anomalous components, $\Delta X_{n}, \Delta Y_{n}$ and $\Delta Z_{n}$ are normal components.

Now we assume that $\Delta Z_{n}, \delta X, \delta Y$ and $\delta Z$ are negligibly small and a normal field is observed at a reference station. Then we get:

$$
\left(\begin{array}{c}
\Delta X_{s} \\
\Delta Y_{s} \\
\Delta Z_{s}
\end{array}\right)=\left(\begin{array}{c}
\Delta X_{r} \\
\Delta Y_{r} \\
0
\end{array}\right)+\left(\begin{array}{cc}
C & D \\
E & F \\
A & B
\end{array}\right) \cdot\left(\begin{array}{c}
\Delta X_{r} \\
\Delta Y_{r}
\end{array}\right)=\left(\begin{array}{cc}
C+1 & D \\
E & F+1 \\
A & B
\end{array}\right) \cdot\left(\begin{array}{l}
\Delta X_{r} \\
\Delta Y_{r}
\end{array}\right)
$$

where $\Delta X_{r}$ and $\Delta Y_{r}$ are the horizontal components of geomagnetic variations of a reference station.

To calculate the interstation transfer functions, synchronous observations at the field station and the reference station are needed. Timing of the observations at each first order geomagnetic station is within 3 seconds, which is sufficiently accurate to calculate the interstation transfer functions of both the geomagnetic vertical and horizontal fields, since we calculated the transfer functions for the periods from $4 \mathrm{~min}$ to $128 \mathrm{~min}$ and the phase error is at most 5 degrees $(3 \mathrm{sec} / 4 \mathrm{~min}$ ).

We selected KAK as the reference observatory because KAK is situated in the central part of Japan 
Table 2. Coherency squared of each component between KAK and each observatory (June 1993).

\begin{tabular}{|c|c|c|c|c|c|c|c|c|c|c|c|c|}
\hline & \multicolumn{3}{|l|}{ MMB } & \multicolumn{3}{|l|}{ MIZ } & \multicolumn{3}{|l|}{ KNZ } & \multicolumn{3}{|l|}{ KNY } \\
\hline & $X$ & $\mathrm{Y}$ & $Z$ & $X$ & $\mathrm{Y}$ & $Z$ & $X$ & Y & $Z$ & $\mathrm{X}$ & Y & 2 \\
\hline $128 \mathrm{~min}$ & .91 & .87 & .10 & .95 & .95 & .16 & .99 & .98 & .95 & .94 & .82 & .63 \\
\hline 64 min & .91 & .89 & .11 & 95 & .95 & .19 & .99 & .98 & .95 & .94 & .85 & .67 \\
\hline $32 \min$ & .85 & .94 & .14 & .98 & .98 & .05 & .98 & .97 & .92 & .94 & .88 & .65 \\
\hline 16 min & .88 & .94 & .03 & .99 & .98 & .11 & .98 & .92 & .83 & .97 & .92 & .76 \\
\hline 8 min & .86 & .96 & .09 & .98 & .98 & .31 & .94 & .79 & .48 & .95 & .94 & .73 \\
\hline 4 min & .90 & .88 & .02 & .93 & .86 & .28 & .53 & .26 & .06 & .93 & .82 & .53 \\
\hline
\end{tabular}

and we can use reliable data for the duration of all the field observations.

When there is a local noise in the data of a station, we can reduce the effect of the noise using data at other stations. This technique is called the remote reference method, which was developed in magnetotelluric studies (Gamble et al., 1979). In this study, we have calculated the interstation transfer functions by a method similar to remote reference. The interstation method is effective if there is noise that is not coherent from one station to another but the method does not work well if either the noise is coherent or if the input external signal is incoherent. In this study, the distance between the field stations and the reference station KAK is at least $18 \mathrm{~km}$ (TKB) and coherent artificial noise was not found. The distance is at most one thousand kilometers. The wave-length of substorm events is several thousand kilometers at mid-latitude (Camfield and Gough, 1975) and therefore we can assume that KAK and the field stations are within the same external field. Table 2 shows squared coherency of the three components of the geomagnetic field between KAK and other observatories. Generally, the squared coherency of the horizontal field is greater than 0.8 except for that with $\mathrm{KNZ}$ at shorter periods (probably due to artificial noises which are clearly seen in the data from KNZ). The coherency is at least 0.85 between KAK and MMB in northern Japan. As the input signal of the reference horizontal field is coherent, and local anomalous fields and noise are generally small at both the reference station and the field stations, the interstation method can be utilized in this study to reduce the effect of noise. In Subsection 5.1, the choice of KAK as the reference station will be further discussed.

\subsection{Method of analysis}

In this study, the transfer functions are obtained by making use of the power spectrum analysis method (Everett and Hyndman, 1967). We get the transfer functions using the following formula:

$$
\begin{aligned}
& A=\frac{P_{Z_{s} X_{r}} \cdot P_{Y_{r} Y_{r}}-P_{Y_{r} X_{r}} \cdot P_{Z_{s} Y_{r}}}{P_{X_{r} X_{r}} \cdot P_{Y_{r} Y_{r}}-P_{X_{r} Y_{r}} \cdot P_{Y_{r} X_{r}}} \\
& B=\frac{P_{Z_{s} Y_{r}} \cdot P_{X_{r} X_{r}}-P_{X_{r} Y_{r}} \cdot P_{Z_{s} X_{r}}}{P_{X_{r} X_{r}} \cdot P_{Y_{r} Y_{r}}-P_{X_{r} Y_{r}} \cdot P_{Y_{r} X_{r}}} \\
& C=\frac{P_{X_{s} X_{r}} \cdot P_{Y_{r} Y_{r}}-P_{Y_{r} X_{r}} \cdot P_{X_{s} Y_{r}}}{P_{X_{r} X_{r}} \cdot P_{Y_{r} Y_{r}}-P_{X_{r} Y_{r}} \cdot P_{Y_{r} X_{r}}}-1 \\
& D=\frac{P_{X_{s} Y_{r}} \cdot P_{X_{r} X_{r}}-P_{X_{r} Y_{r}} \cdot P_{X_{s} X_{r}}}{P_{X_{r} X_{r}} \cdot P_{Y_{r} Y_{r}}-P_{X_{r} Y_{r}} \cdot P_{Y_{r} X_{r}}}
\end{aligned}
$$




$$
\begin{aligned}
& E=\frac{P_{Y_{s} X_{r}} \cdot P_{Y_{r} Y_{r}}-P_{Y_{r} X_{r}} \cdot P_{Y_{s} Y_{r}}}{P_{X_{r} X_{r}} \cdot P_{Y_{r} Y_{r}}-P_{X_{r} Y_{r}} \cdot P_{Y_{r} X_{r}}} \\
& F=\frac{P_{Y_{s} Y_{r}} \cdot P_{X_{r} X_{r}}-P_{X_{r} Y_{r}} \cdot P_{Y_{s} X_{r}}}{P_{X_{r} X_{r}} \cdot P_{Y_{r} Y_{r}}-P_{X_{r} Y_{r}} \cdot P_{Y_{r} X_{r}}}-1
\end{aligned}
$$

where $P_{X_{r} X_{r}}, P_{Y_{r} Y_{r}}$ denote the auto-power spectra and $P_{X_{r} Y_{r}}, P_{Y_{r} X_{r}}, P_{X_{s} X_{r}}, P_{Y_{s} X_{r}}$, and $P_{Z_{r} Y_{r}}$ etc. the cross-power spectra.

Initially, the raw data of three components of the geomagnetic variations were checked by visual inspection of time series and we eliminated bad data. They were then rotated to the geographical coordinate and partitioned into 8 hour data segments. A digital high-pass filter (cut off period of $140 \mathrm{~min}$ ) and a hanning window were applied to each partitioned data set. Auto- and cross-power spectra for each data segment were then calculated using an FFT, and smoothed in frequency. Transfer functions are generally obtained by averaging a subset of the transfer functions that are selected on the basis of the signal power and the coherency. However, in this study a simpler method was used in which we calculated the transfer functions using auto- and cross-power spectra for all stacked data. Confidence intervals (95\%) were estimated by the method described by Bendat and Piersol (1971).

\subsection{Evaluation of the accuracy of the transfer functions}

As the transfer functions are possibly affected by external $\Delta Z$, similar changes of the geomagnetic transfer functions are sometimes found at two stations some distance apart (Sano et al., 1982). Geomagnetic activity varies considerably with time and therefore it has been argued that transfer functions are unstable, particularly when the power of the external horizontal field is small or the coherency between $\Delta X$ and $\Delta Y$ is large (Shiraki, 1980). In this section, we discuss the accuracy of the transfer functions at the first order geomagnetic stations.

Figure 2 shows the standard deviation of the transfer functions $A$ and $B$ at KAK with increasing numbers of stacked data, for which each stack represents 8 hours of observation. It is clear that the standard deviation becomes smaller as the stacking number becomes larger. As the duration of continuous observations is about 40 hours or more at each first order geomagnetic station, we checked the standard

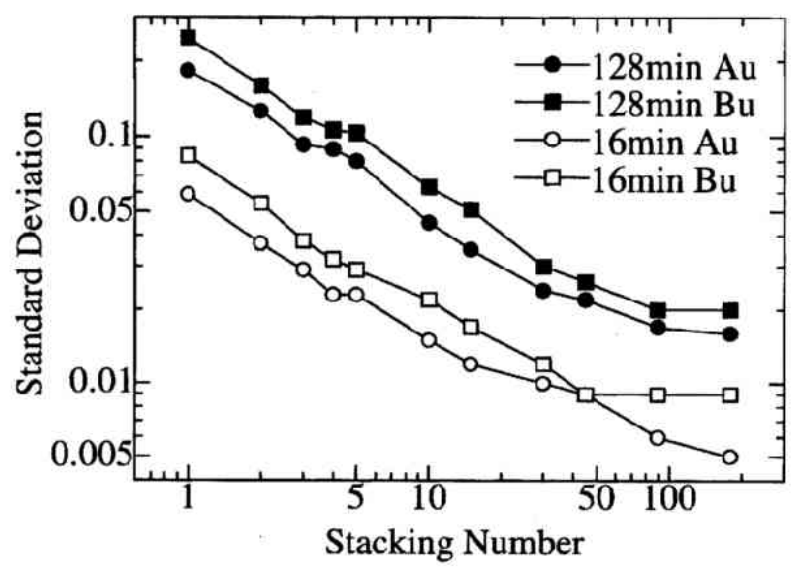

Fig. 2. Standard deviations of the real part of the transfer function $A$ and $B$ at KAK according to stacking number in 1989. The real and imaginary parts are donated with suffixes $u$ and $v$, respectively. 


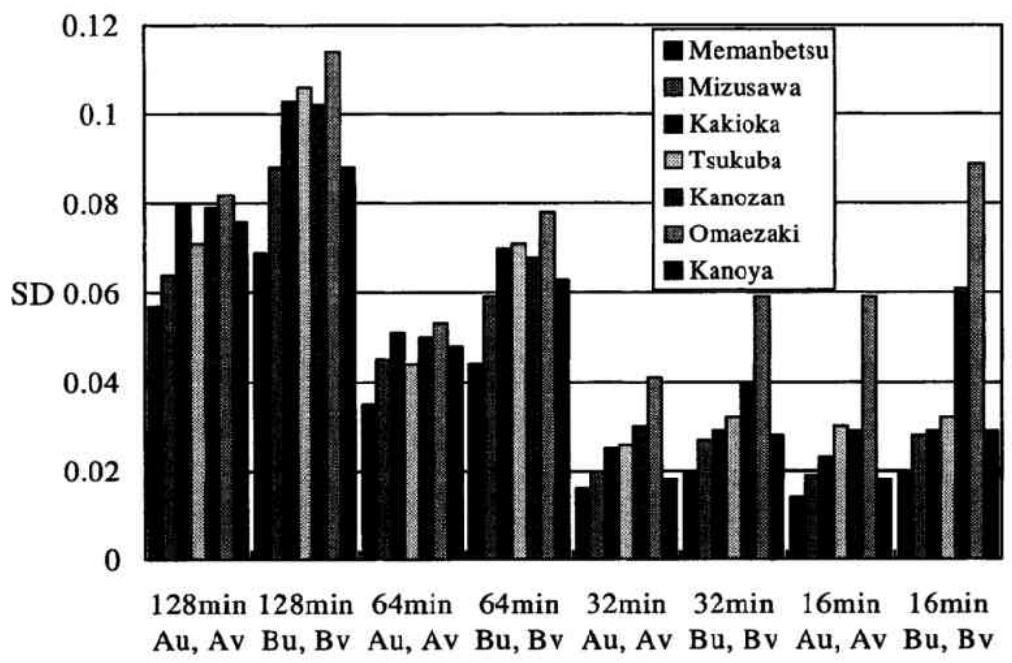

Fig. 3. Standard deviations of the transfer function $A$ and $B$ at each observatory in 1989. Each transfer function was calculated from 40 hour data (5 stacking).

deviations of $A$ and $B$ at each observatory using power spectral estimates from 5 data segments ( 40 hours). In Fig. 3, it can be seen that the accuracy of the transfer function is frequency dependent, and varies between observatories. The accuracy (estimated by the standard deviation) of $B$ at the period of $128 \mathrm{~min}$ is the worst, and is about 0.1 . We note that secular variations and seasonal variations in the observatories' transfer functions (Fujita, 1989) will tend to increase the standard deviations. The average confidence intervals of all first order geomagnetic stations are at most 0.04 of $B$ at periods of $128 \mathrm{~min}$ and $4 \mathrm{~min}$. The confidence estimates of the transfer functions at the first order geomagnetic stations are therefore smaller than that due to the secular and the seasonal variations. For all stations and observatories the accuracy is better than 0.1 which is sufficient to examine the nation wide distribution of transfer functions.

4. Geographical Distributions of the Transfer Functions in Japan

\subsection{Results at geomagnetic stations}

(a) Induction arrows

We have two types of transfer functions from the single-station and interstation methods. The singlestation transfer functions $A_{s}$ and $B_{s}$, that are defined in Eq. (1), are given by

$$
\Delta Z_{s}=A_{s} \cdot \Delta X_{s}+B_{s} \cdot \Delta Y_{s}
$$

Similarly, interstation transfer functions $A_{i}$ and $B_{i}$, that are defined in Eq. (3), are given by

$$
\Delta Z_{s}=A_{i} \cdot \Delta X_{r}+B_{i} \cdot \Delta Y_{r}
$$

In Eq. (1), $\Delta X$ and $\Delta Y$ are considered as normal fields, and the anomalous horizontal fields are negligibly small. However, we have found that large anomalous horizontal fields exist in some places that cannot be neglected. From Eqs. (3) and (10) we have 


$$
\begin{aligned}
& A_{s}=A_{r}=\frac{A_{i} \cdot F-B_{i} \cdot E}{C \cdot F-D \cdot E}, \\
& B_{s}=B_{r}=\frac{B_{i} \cdot C-A_{i} \cdot D}{C \cdot F-D \cdot E} .
\end{aligned}
$$

In these equations, $A_{s}$ and $B_{s}$ are re-defined using only the interstation transfer functions. Hereafter we call induction arrows composed of $A_{s}$ and $B_{s}$ in Eqs. (12) and (13) the remote reference induction arrows $\left(A_{r}\right.$ and $B_{r}$ ).

Figure 4 shows the single-station induction arrows $A_{s}$ and $B_{s}$ in Eq. (10) and Fig. 5 shows the remote reference induction arrows $A_{r}$ and $B_{r}$ in Eqs. (12) and (13) for comparison. At a glance, the single-station induction arrows are quite similar to the remote reference induction arrows, because the input external fields have high coherency and are almost the same at KAK and the stations (Table 2).

There are fluctuations of a few $\mathrm{nT}$ at periods of shorter than a few tens of minutes at some stations. They are mainly caused by leaked currents from DC electric railways. Artificial noises dominate the transfer functions at some stations and it is difficult to remove such effects automatically using singlestation data only. However, using the interstation method, we can estimate the noise contamination. For example, in Fig. 4, single-station induction arrows of a few stations (e.g. No. 5 Imazu and No. 45 Inuyama) have quite unusual values as compared with those of the neighboring stations due to artificial noise. By use of a remote reference, induction arrows become more consistent with neighboring stations or can be rejected because of large estimated errors (note that when the estimated standard deviations are greater than 0.2 , transfer functions are not used). Remote reference induction arrows were therefore used in this study instead of the traditional single-station induction arrows.

\section{(b) Horizontal transfer function}

Horizontal transfer functions $C, D, E$ and $F$ include information of anomalous fields and can be used to estimate electrical resistivity structures of the Earth. There are several methods of portraying these horizontal transfer functions on a map that displays anomalous magnetic fields or electrical resistivity structures. However, an optimum method has notyet to be found (Lilley, 1974). In this paper we have used and refined a method, developed by Beamish (1982), of plotting the anomalous horizontal field rotation ellipses. The purpose of this graphical method is to summarize the response of $\Delta X_{s}$ and $\Delta Y_{s}$ compared with $\Delta X_{r}$ and $\Delta Y_{r}$. We assume a regional horizontal fields $\Delta X_{r}$ and $\Delta Y_{r}$ at the reference station which results in anomalous horizontal fields $\Delta X_{a}$ and $\Delta Y_{a}$ at field stations.

The horizontal field at a field station

$$
s=\left(\Delta X_{s}, \Delta Y_{s}\right)
$$

is divided into reference (normal) field

$$
\boldsymbol{r}=\left(\Delta X_{r}, \Delta Y_{r}\right)
$$

and anomalous field

$$
\boldsymbol{a}=\left(\Delta X_{a}, \Delta Y_{a}\right) .
$$

Therefore,

$$
\boldsymbol{s}=\boldsymbol{r}+\boldsymbol{a}=\boldsymbol{r}+\left(\begin{array}{ll}
C & D \\
E & F
\end{array}\right) \boldsymbol{r} .
$$


(a)

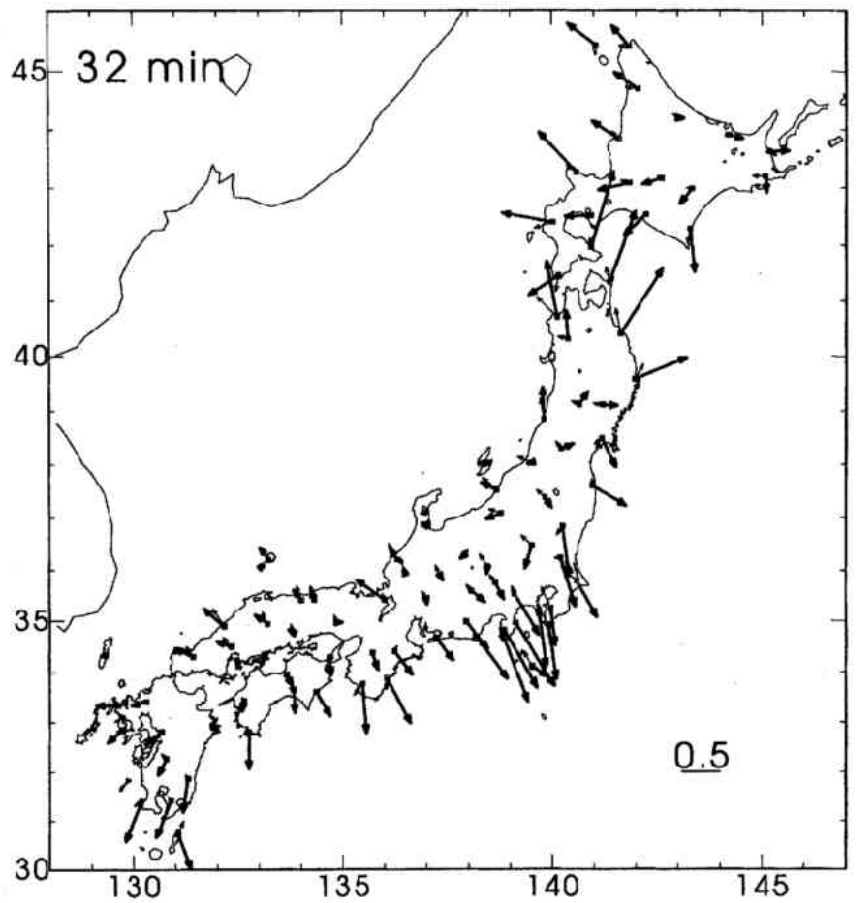

(b)

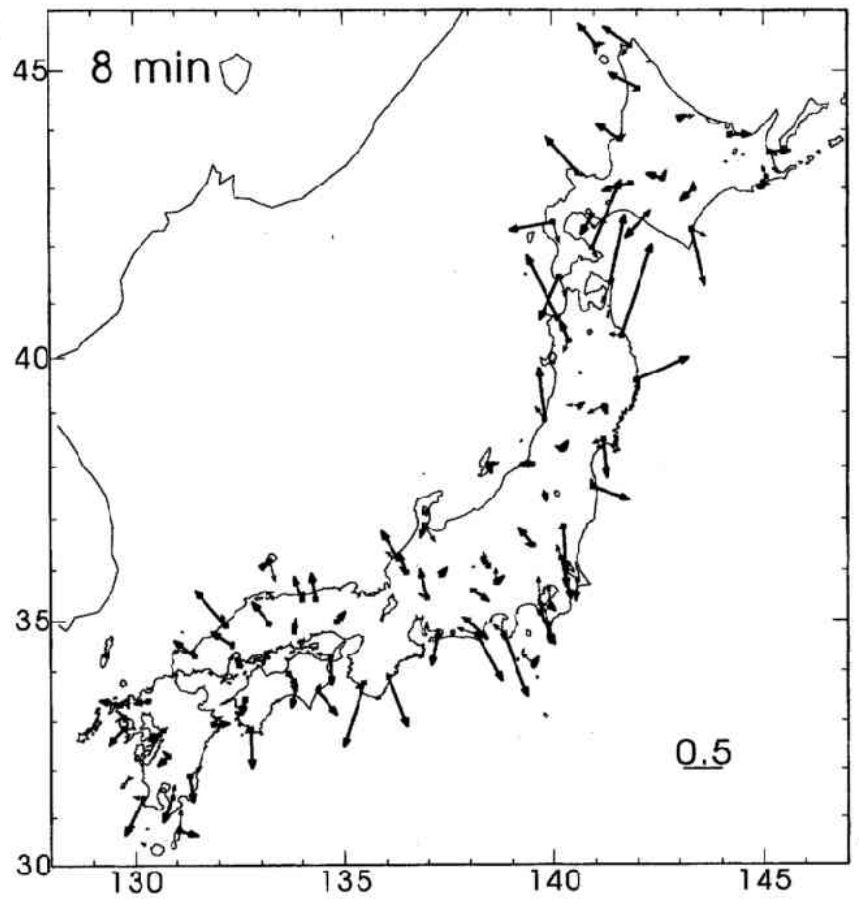

Fig. 4. Single-station induction arrows. The thick line with a large arrowhead shows a real part ( $A u$ and $B u$ ) and the thin line with a small arrowhead shows an imaginary part $(A v$ and $B v)$. 
(a)

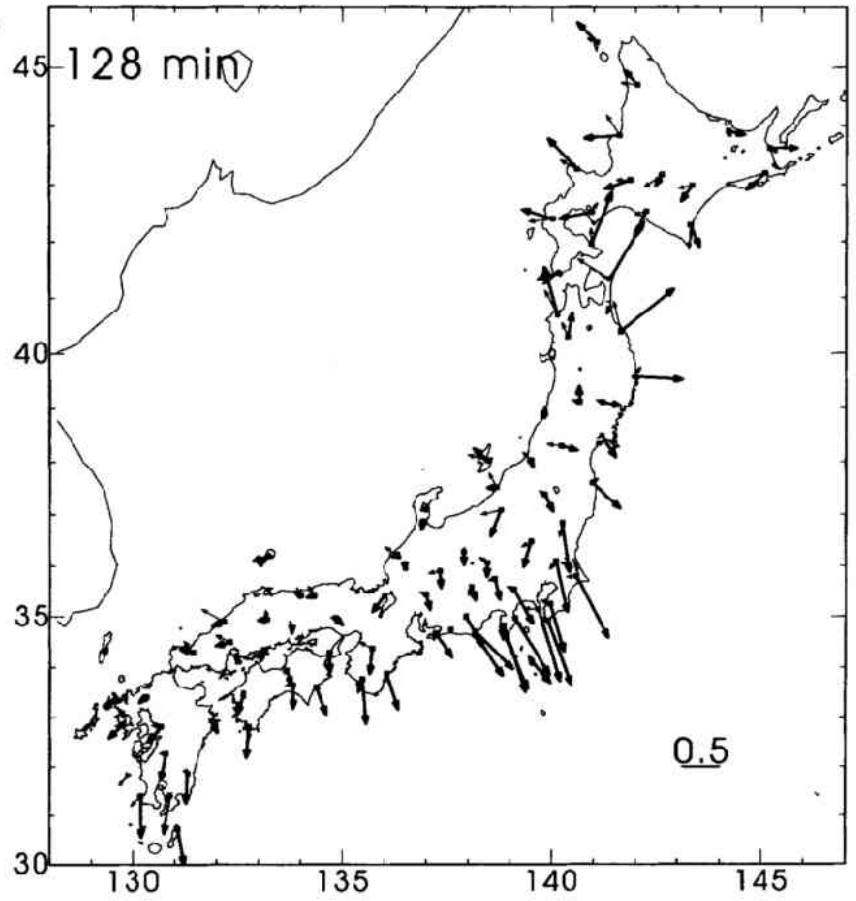

(b)

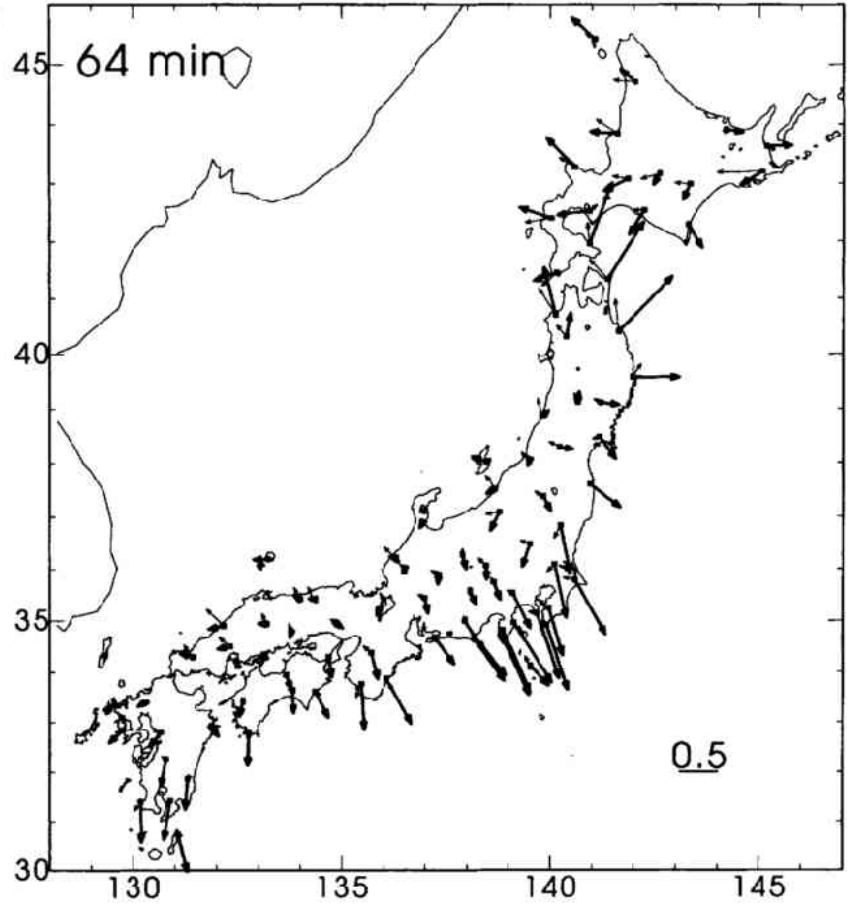

Fig. 5. Observed remote reference induction arrows. The thick line with a large arrowhead shows a real part and the thin line with a small arrowhead shows an imaginary part. 
(c)

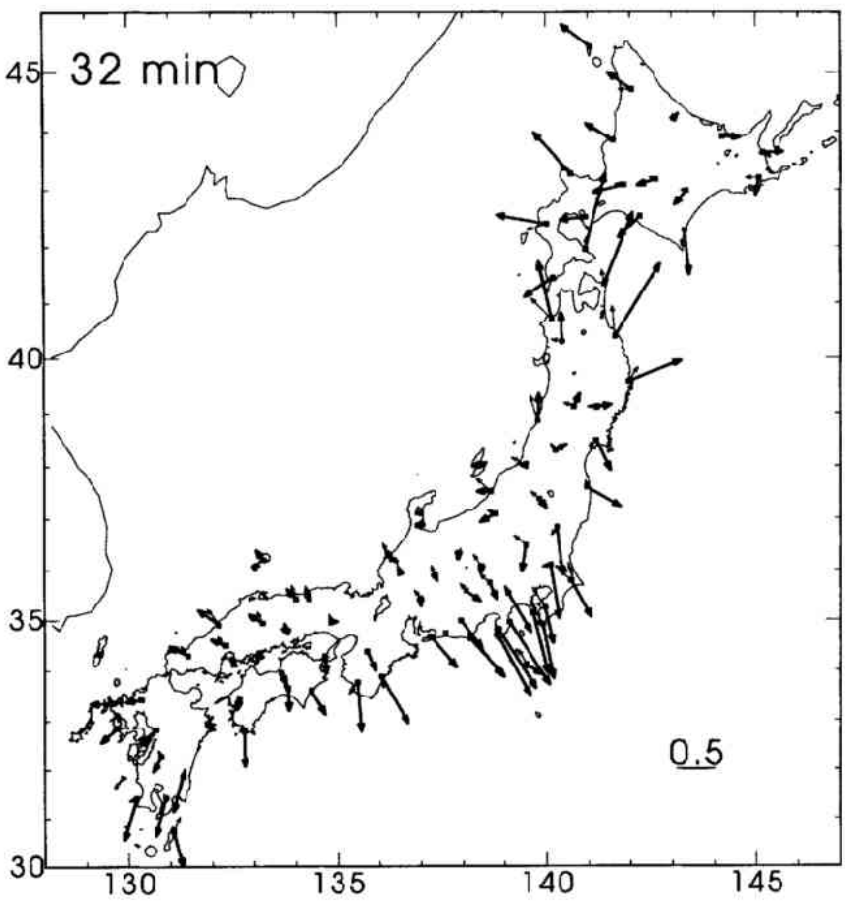

(d)

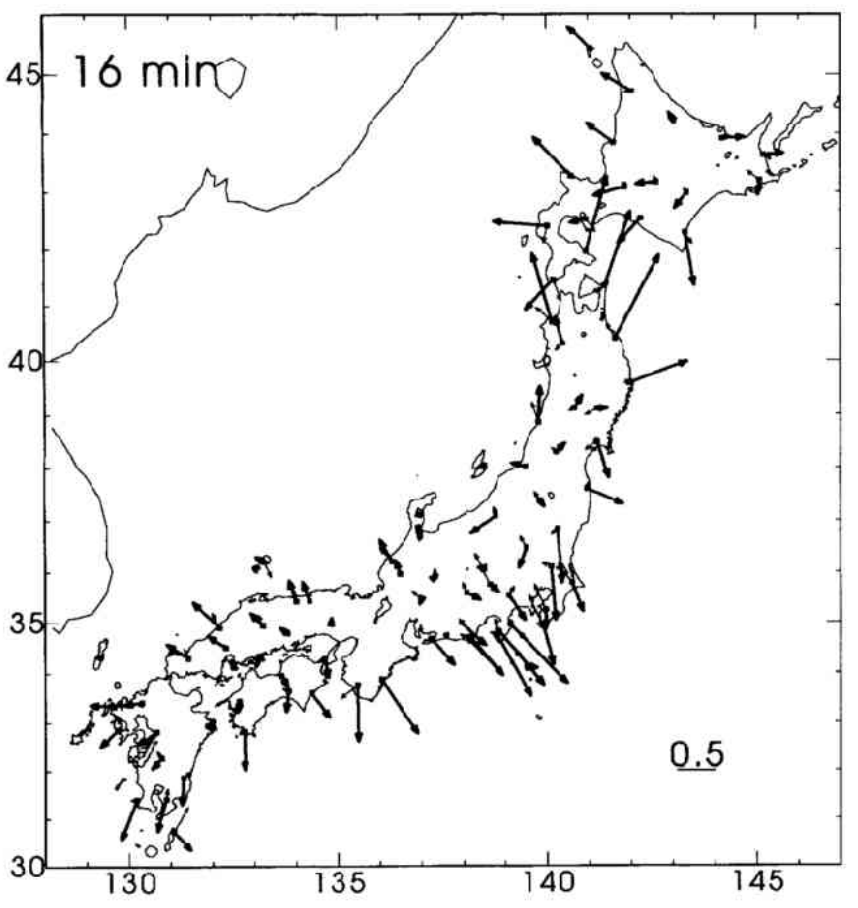

Fig. 5. (continued). 
(e)

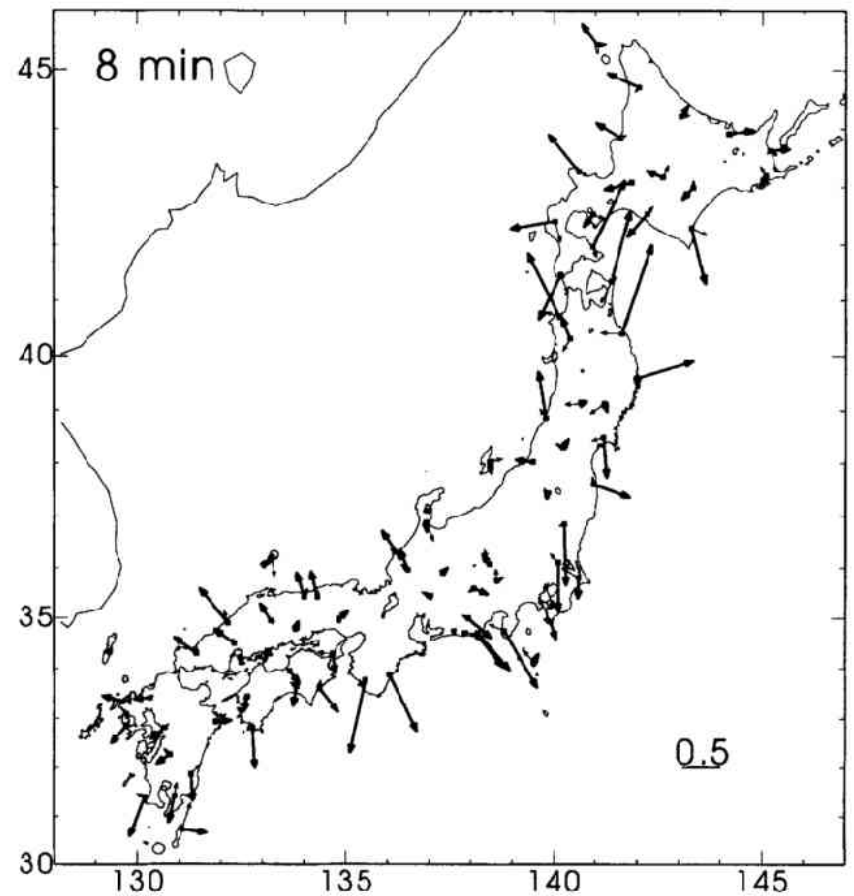

(f)

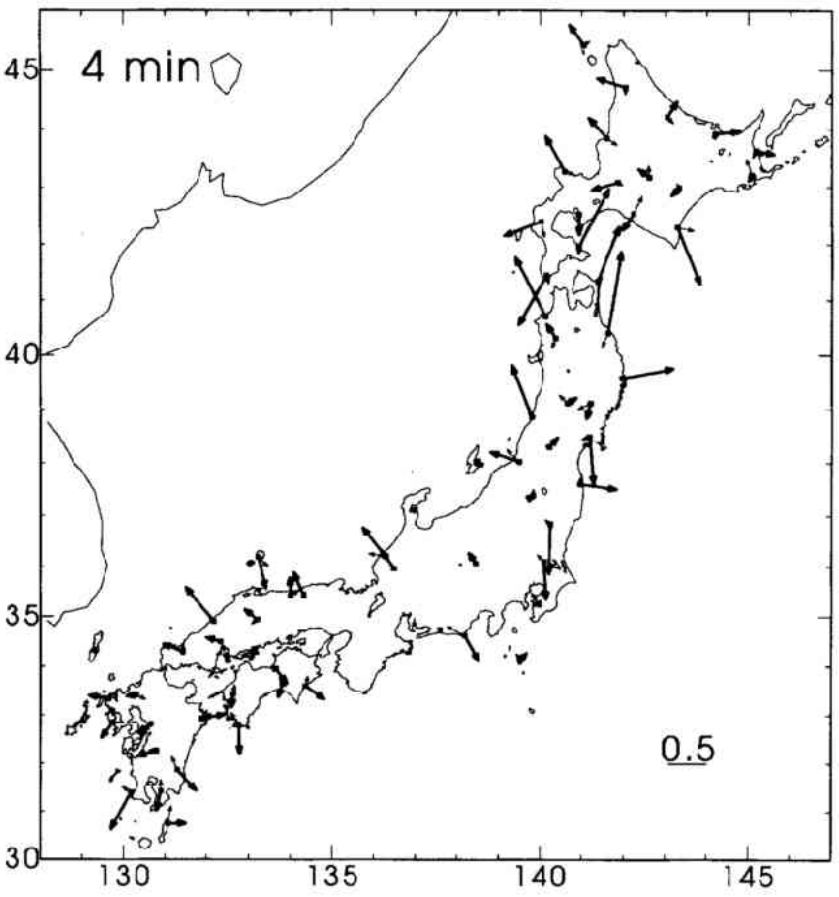

Fig. 5. (continued). 
Now we define that $\boldsymbol{r}$ has unit amplitude and zero phase so that it is normalized according to external reference field. Hence,

$$
\boldsymbol{r}=(\sin \theta, \cos \theta)
$$

so $|\boldsymbol{r}|=1,0^{\circ} \leq \theta<360^{\circ}$, and

$$
\begin{aligned}
& \boldsymbol{s}=\left(\begin{array}{l}
\sin \theta \\
\cos \theta
\end{array}\right)+\left(\begin{array}{ll}
C & D \\
E & F
\end{array}\right)\left(\begin{array}{l}
\sin \theta \\
\cos \theta
\end{array}\right), \\
& \boldsymbol{a}=\left(\begin{array}{ll}
C & D \\
E & F
\end{array}\right)\left(\begin{array}{l}
\sin \theta \\
\cos \theta
\end{array}\right) .
\end{aligned}
$$

These $s$ and $a$ can be plotted as a point in a plane (Fig. 6(a)). As the angle $\theta$ is changed, each points will trace out the locus of an ellipse. The radii of the ellipses are proportional to the anomalous field, which is induced by anomalous current in the Earth. We define the anomalous horizontal field rotation ellipses as locus of $\boldsymbol{a}$. Figure 6(b) shows an example of the anomalous ellipse of the horizontal transfer function. In this expression, a bold line shows $|\boldsymbol{s}|>1$ and a broken line shows $|\boldsymbol{s}|<1$. The direction of the anomalous current flow, which tends to coincide with the strike direction of low resistivity anisotropy, is normal to the major or minor axis of the anomalous ellipses of the horizontal transfer function.

Regional resistivity structure causes the directional anomaly of electric currents, e.g. through channeling effects. Although geomagnetic variations induce currents normal to the geomagnetic variations, the direction of electric current is deflected by local and regional resistivity structures. We have added a new expression of this directional anomaly of currents to the anomalous ellipses of the horizontal transfer function. The anomalous fields $\boldsymbol{a}$ of $\theta=180^{\circ}$ (west) and $\theta=270^{\circ}$ (south) are written in terms of the anomalous ellipse as

$$
\begin{aligned}
& \theta=180^{\circ} \rightarrow\left(\begin{array}{l}
\Delta X_{r} \\
\Delta Y_{r}
\end{array}\right)=\left(\begin{array}{c}
0 \\
-1
\end{array}\right) \rightarrow\left(\begin{array}{l}
\Delta X_{a} \\
\Delta Y_{a}
\end{array}\right)=\left(\begin{array}{l}
-D \\
-F
\end{array}\right), \\
& \theta=270^{\circ} \rightarrow\left(\begin{array}{l}
\Delta X_{r} \\
\Delta Y_{r}
\end{array}\right)=\left(\begin{array}{c}
-1 \\
0
\end{array}\right) \rightarrow\left(\begin{array}{l}
\Delta X_{a} \\
\Delta Y_{a}
\end{array}\right)=\left(\begin{array}{l}
-C \\
-E
\end{array}\right) .
\end{aligned}
$$

Then

$$
\begin{aligned}
& a_{\text {west }}=(-D,-F), \\
& a_{\text {south }}=(-C,-E) .
\end{aligned}
$$

These variables can be used to interpret the anomalous current (Fig. 6(c)).

Figure 7 shows the observed anomalous ellipses of the horizontal transfer functions at all stations. Each element of the horizontal transfer functions $C, D, E$ and $F$ has a real (Figs. 7(a)-(f)) and imaginary part (Fig. $7(\mathrm{~g})$ ). Since the imaginary part is much smaller than the real part, we will use the real part in the following discussion. 


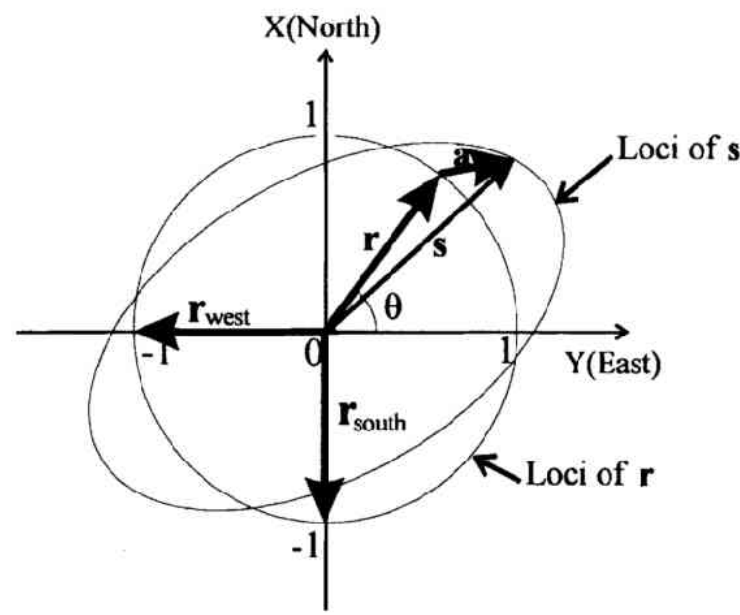

(a)

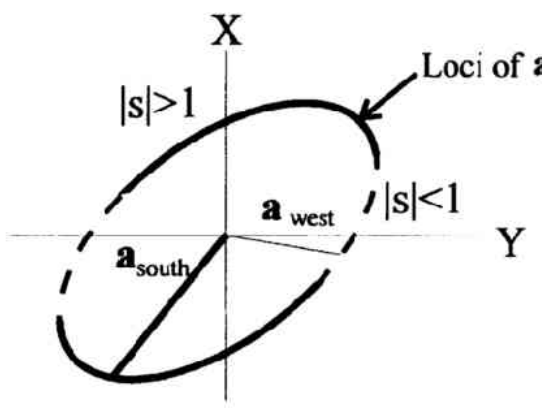

(b)

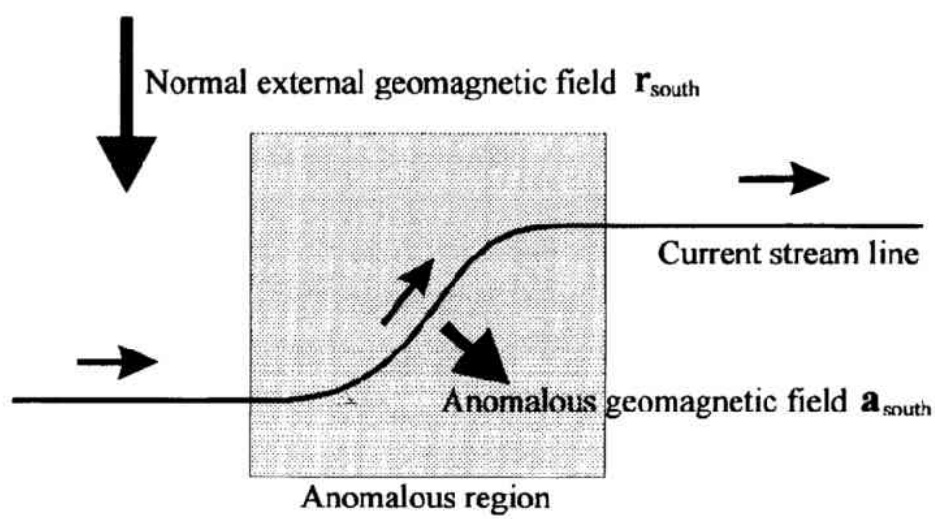

(c)

Fig. 6. (a) Expression of horizontal transfer functions. (b) An example of the anomalous ellipse of the horizontal transfer function. Thick line of the ellipse shows $|s|>1$ and broken line shows $|s|<1$. (c) Schematic explanation of normal and anomalous ficld and current. 
(a)

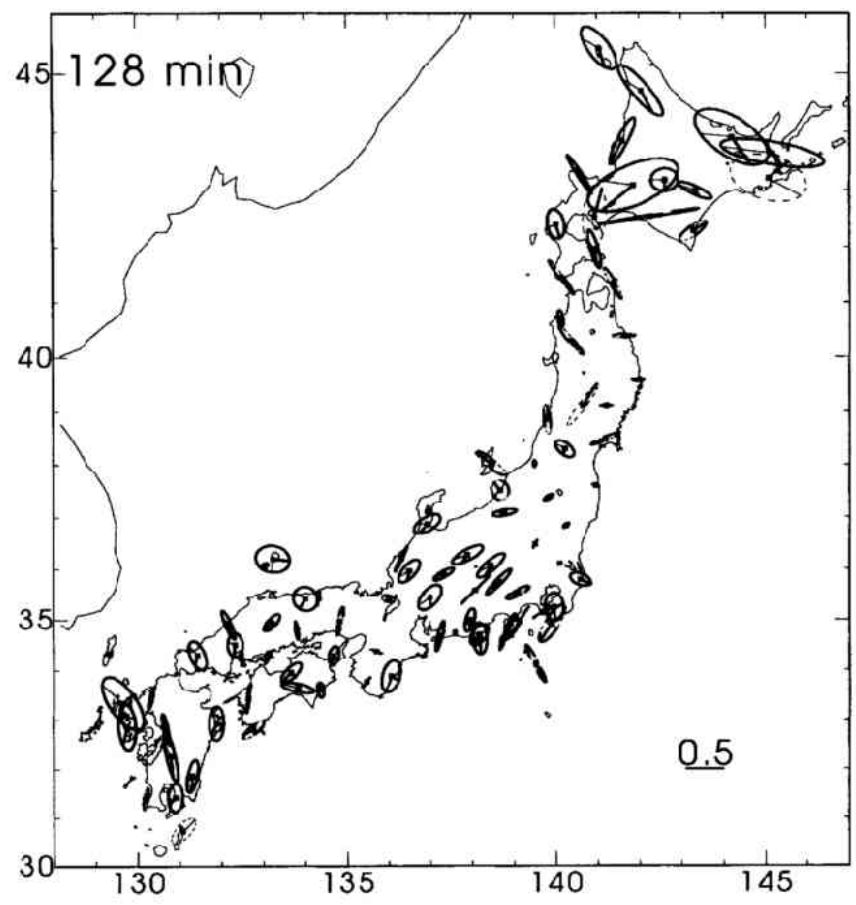

(b)

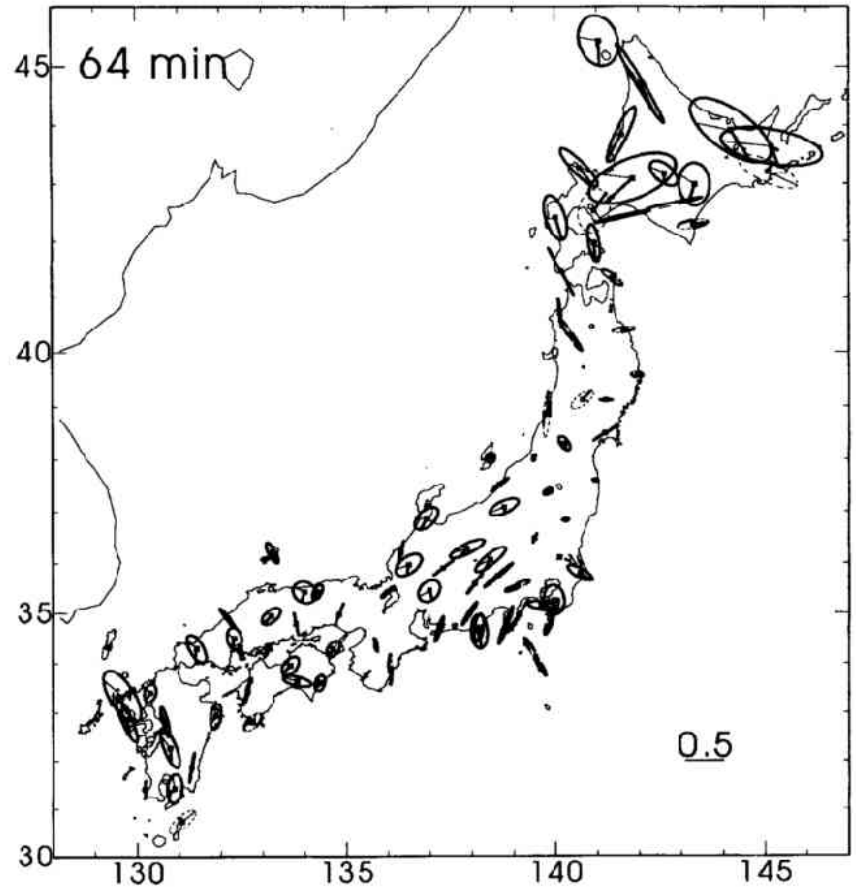

Fig. 7. (a)-(f) Observed anomalous ellipses of horizontal transfer functions (real part). 
(c)

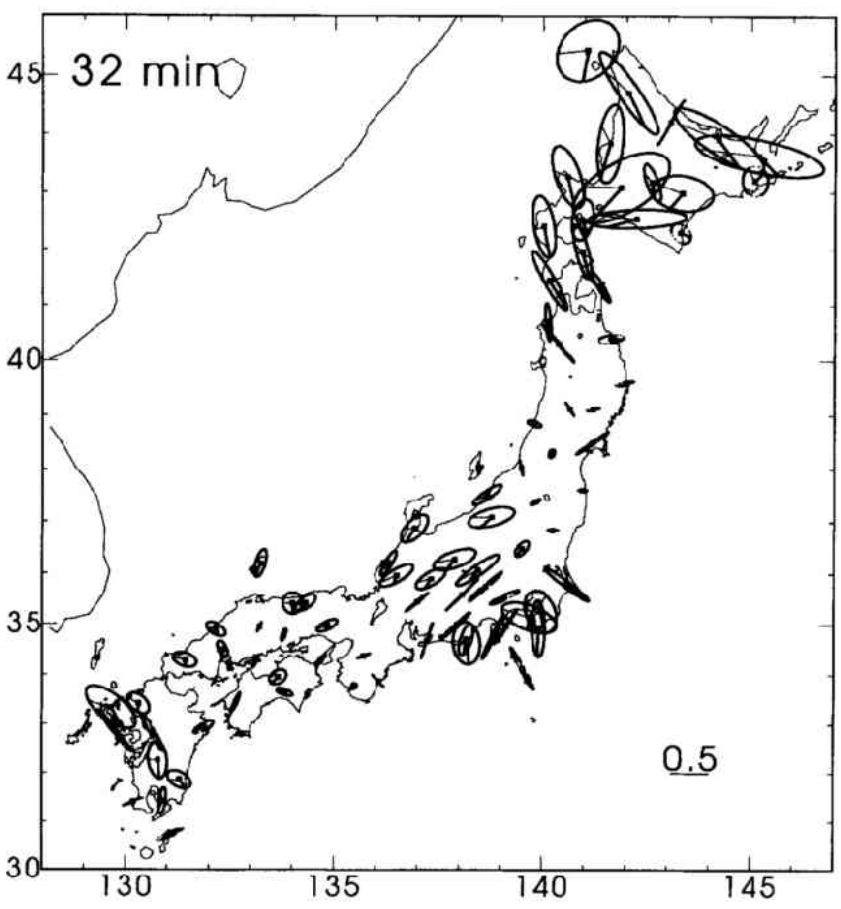

(d)

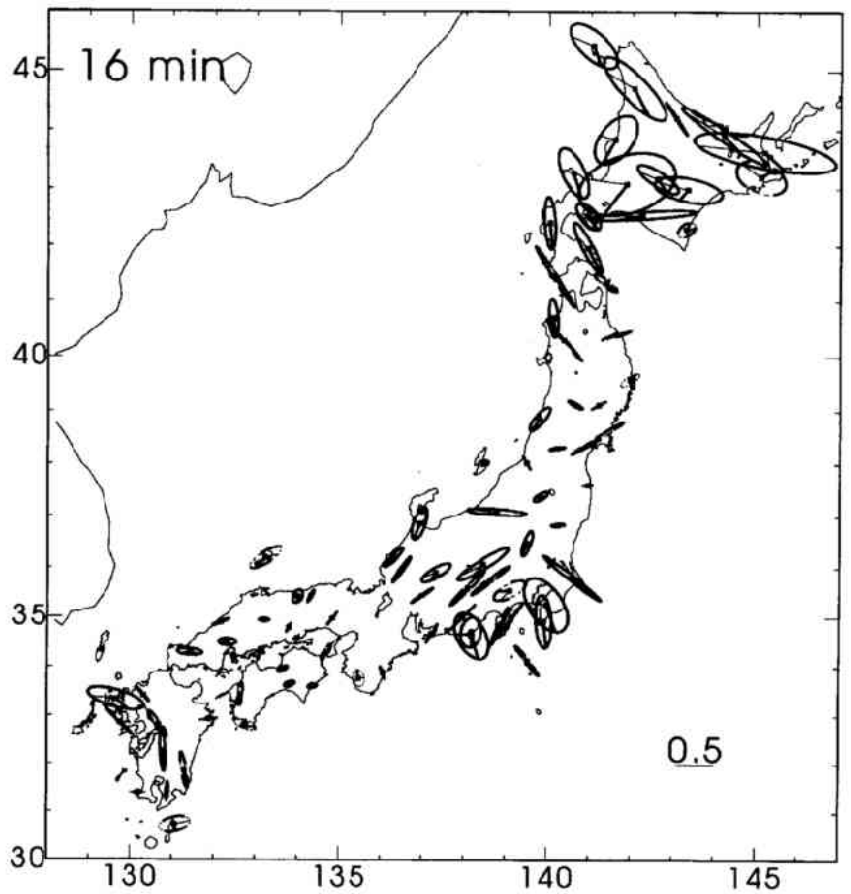

Fig. 7. (continued). 
(e)

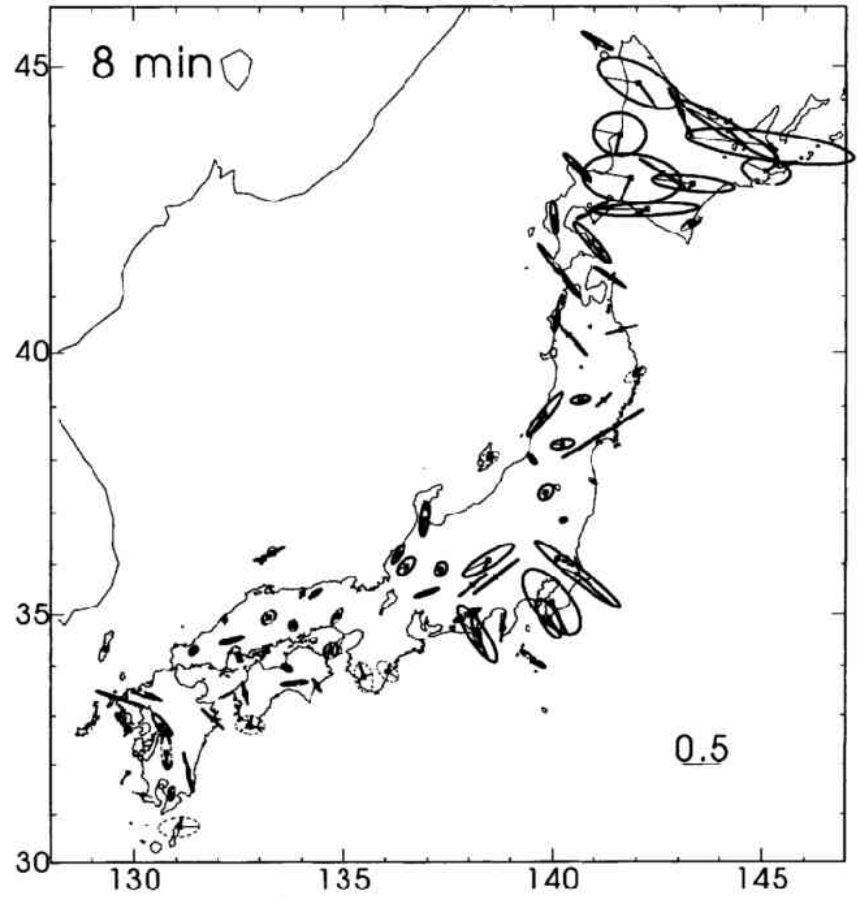

(f)

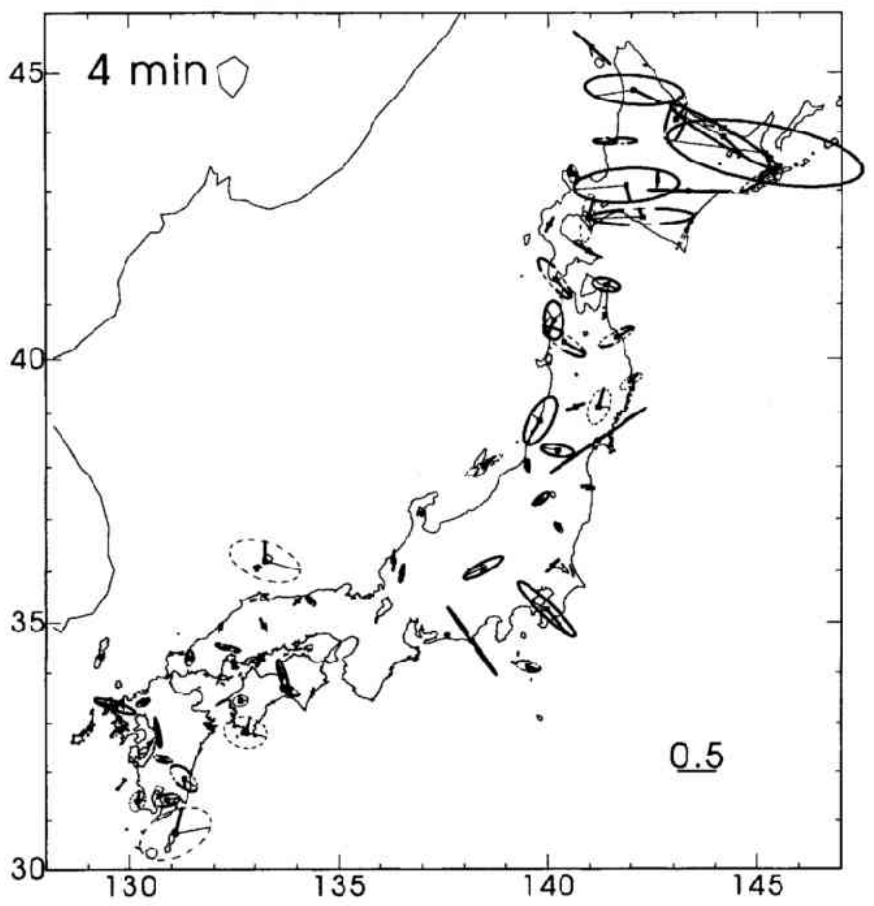

Fig. 7. (continued). 
(g)

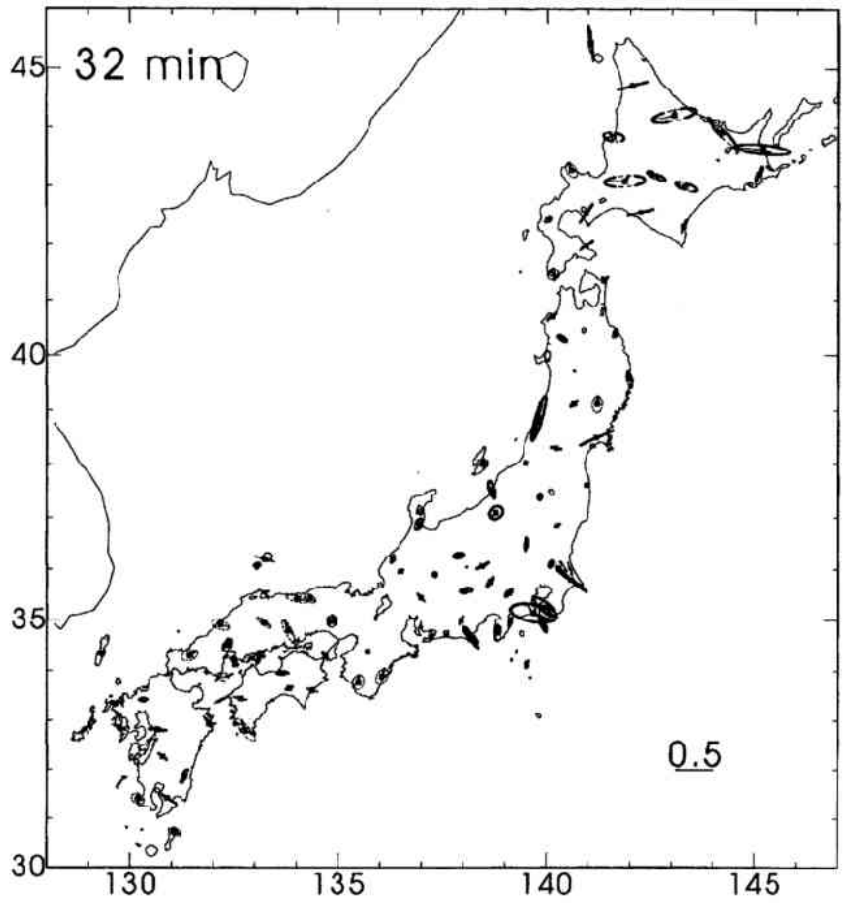

Fig. 7. (g) Observed anomalous ellipses of horizontal transfer functions (imaginary part).

\subsection{Thin-sheet modeling}

As sea water has low electrical resistivity, the ocean effect on the transfer functions can be large. To remove the ocean effect we applied numerical calculation using McKirdy et al.'s (1985) thin-sheet algorithm. In a similar study, Chamalaun and McKnight (1993) applied this method in New Zealand. The resistivity structure of the crust is too complex to model and so we estimated only the sea water effect in this study, as a first approximation.

McKirdy et al.'s (1985) method includes a thin layer (known as a thin-sheet) of laterally varying conductance overlying a layered resistivity structure, representing the crust and upper mantle. In this study, the layer just below the thin-sheet is $80 \mathrm{~km}$ thick and has a resistivity of $250 \mathrm{ohm} \cdot \mathrm{m}$, and the bottom layer is a half space with resistivity of $10 \mathrm{ohm} \cdot \mathrm{m}$. In this model, the upper layer represents the upper lithosphere and the lower layer represents the lower lithosphere and the asthenosphere (e.g. Filloux, 1980; Bapat et al., 1993). The resistivity and the thickness of the layer just below the surface thin-sheet are very important parameters in the sense that (1) the resistivity governs penetration of poloidal electric currents in the thin-sheet into the substratum, and (2) the thickness determines to what extent toroidal electric currents within the thin-sheet mutually couple with those within deep conductors. Bapat et al. (1993) conducted thin-sheet model studies using a similar 1D structure (a $80 \mathrm{~km}$ thick lithosphere and an asthenospheric conductor of $10 \mathrm{ohm} \cdot \mathrm{m}$ ) beneath the thin-sheets though they used different thin-sheet algorithm based on Vasseur and Weidelt (1977) and a value of $1000 \mathrm{ohm} \cdot \mathrm{m}$ as the resistivity of the layer just below the thin-sheet. We used $250 \mathrm{ohm} \cdot \mathrm{m}$ for the sake of a finer grid spacing since all the lengths appeared in the thin-sheet calculations were normalized by the skin depth in the layer just below the thinsheet. (It results in a coarse grid spacing if we put a high resistivity layer beneath the thin-sheet.) Coarseness of the numerical grids tends to result in smaller vertical magnetic components and consequently smaller amplitudes of the calculated induction arrows (Agarwal and Weaver, 1989) since vertical 
magnetic component is closely related to horizontal spatial derivatives of horizontal electric components by Faraday's law of induction $(\partial E y / \partial x-\partial E x / \partial y=-i \omega \mu Z)$. It, however, was also examined by several direct comparisons that introduction of a higher resistivity layer did not yield any significant differences in the calculated induction arrows. It also turned out, in the course of such examination, that damping by the deep conductor through mutual coupling governed the amplitudes of the calculated induction arrows rather than the resistivity value itself. It is not necessarily bad approximation to assume the regional 1D structure around Japan by a $80 \mathrm{~km}$ thick lithosphere and an asthenospheric conductor of $10 \mathrm{ohm} \cdot \mathrm{m}$ beneath, though it is fairly difficult to give a proper $1 \mathrm{D}$ substratum beneath the Japanese islands where intense lateral conductivity contrasts are expected due mainly to subduction of the oceanic plates (the Pacific plate and the Philippine Sea plate).

The boundary condition on the outer boundaries of the grids are $\partial \sigma / \partial x \rightarrow 0$ as $|x| \rightarrow \infty$ and $\partial \sigma / \partial y \rightarrow$ 0 as $|y| \rightarrow \infty$, in which $\sigma$ is the thin-sheet conductance, and $x$ and $y$ are the horizontal coordinates. This condition allows 2D distribution of the surface conductances at lateral infinity, viz., the condition can be regarded as "Neumann-type" boundary condition rather than "Dirichlet" in terms of boundary value problems.

We used a model comprising 51 by 51 grids that covers the Japanese island and the oceans surrounding the Japanese island. Each grid cell size is approximately $40 \mathrm{~km} \times 40 \mathrm{~km}$ and the conductance of each cell is calculated from the ocean depths, assuming the resistivity of sea water to be $0.3 \mathrm{ohm} \cdot \mathrm{m}$ and the land to be $1000 \mathrm{ohm} \cdot \mathrm{m}$. The depth grouping used in this study is in Table 3 and the resultant conductance distribution is shown in Fig. 8.

Model calculations were done only at periods of 32, 64 and 128 min because the thin-sheet assumption breaks down at periods shorter than $32 \mathrm{~min}$. At short periods, the external fields are significantly attenuated within the ocean, which implies that the ocean is too thick to be modelled by any thin-sheets. Figures 9 and 10 show the calculated remote reference induction arrows and the anomalous ellipses of the horizontal transfer functions, respectively.

Table 3. Configuration of each conductance and depth of sea water. $\sigma_{\mathrm{SW}}$ is conductivity of sea water and $\sigma_{\mathrm{L}}$ is that of land.

\begin{tabular}{|c|c|}
\hline Depth of Sea & Mean value \\
\hline $0<d$ & (1000 ohm. m) \\
\hline$-100<d<$ & $50 \mathrm{~m}$ \\
\hline$-200<d<-100$ & $150 \mathrm{~m}$ \\
\hline$-400<d<-200$ & $300 \mathrm{~m}$ \\
\hline$-700<d<-400$ & $550 \mathrm{~m}$ \\
\hline$-1000<d<-700$ & $850 \mathrm{~m}$ \\
\hline$-1500<d<-1000$ & $1250 \mathrm{~m}$ \\
\hline$-2000<d<-1500$ & $1750 \mathrm{~m}$ \\
\hline$-2500<d<-2000$ & $2250 \mathrm{~m}$ \\
\hline$-3000<d<-2500$ & $2750 \mathrm{~m}$ \\
\hline$-3500<d<-3000$ & $3250 \mathrm{~m}$ \\
\hline$-4000<d<-3500$ & $3750 \mathrm{~m}$ \\
\hline$-4500<d<-4000$ & $4250 \mathrm{~m}$ \\
\hline$-5000<d<-4500$ & $4750 \mathrm{~m}$ \\
\hline$-5500<d<-5000$ & $5250 \mathrm{~m}$ \\
\hline$-6000<d<-5500$ & $5750 \mathrm{~m}$ \\
\hline$-6500<d<-6000$ & $6250 \mathrm{~m}$ \\
\hline$-7000<d<-6500$ & $6750 \mathrm{~m}$ \\
\hline$-7500<d<-7000$ & $7250 \mathrm{~m}$ \\
\hline$d<-7500$ & $7750 \mathrm{~m}$ \\
\hline
\end{tabular}

Conductance $=\left(\right.$ depth $\times \sigma_{\mathrm{SW}}+(10000-$ depth $\left.) \times \sigma_{\mathrm{L}}\right) /\left(\right.$ skin depth $\left.\times \sigma_{\mathrm{L}}\right) . \sigma_{\mathrm{SW}}=3.3 \mathrm{~S} / \mathrm{m}$. 


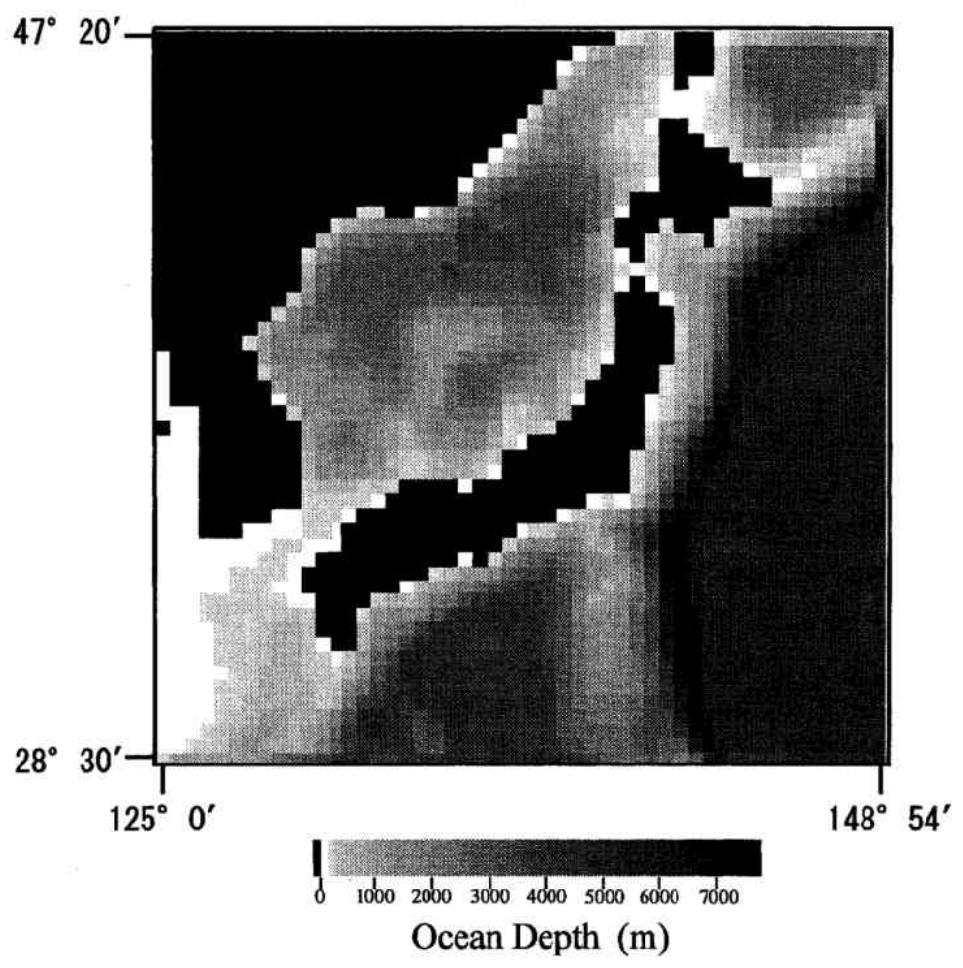

Fig. 8. Ocean depth used in this study at the period of $32 \mathrm{~min}$.

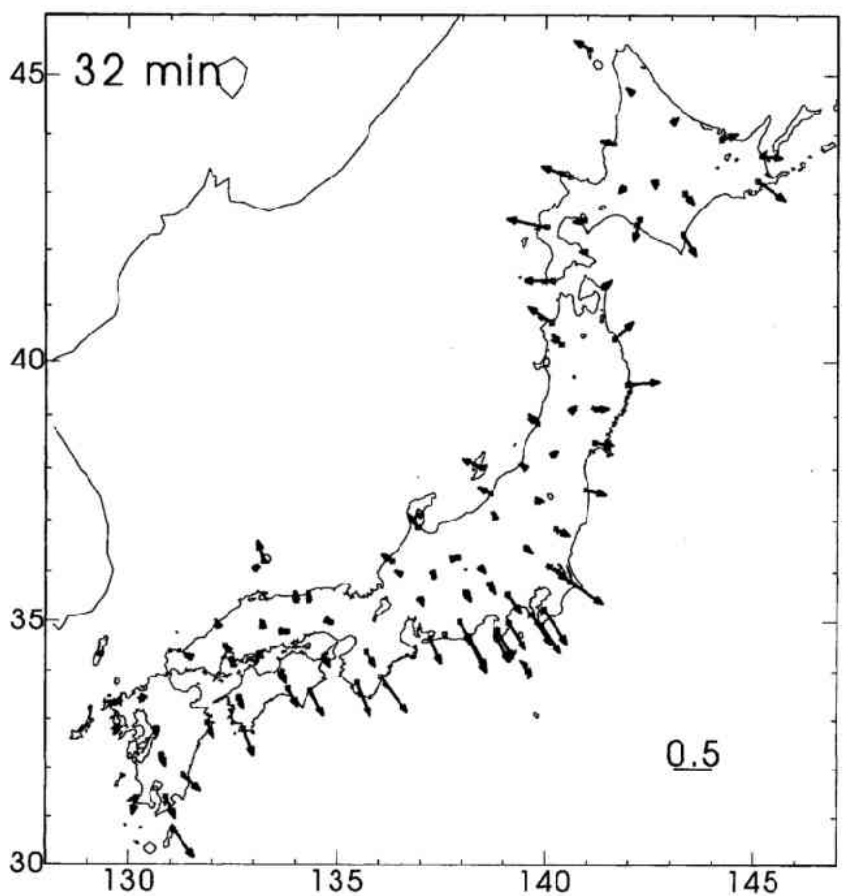

Fig. 9. Induction arrows of the thin-sheet model calculation. The thick line with a large arrowhead shows a real part and the thin line with a small arrowhead shows an imaginary part. 


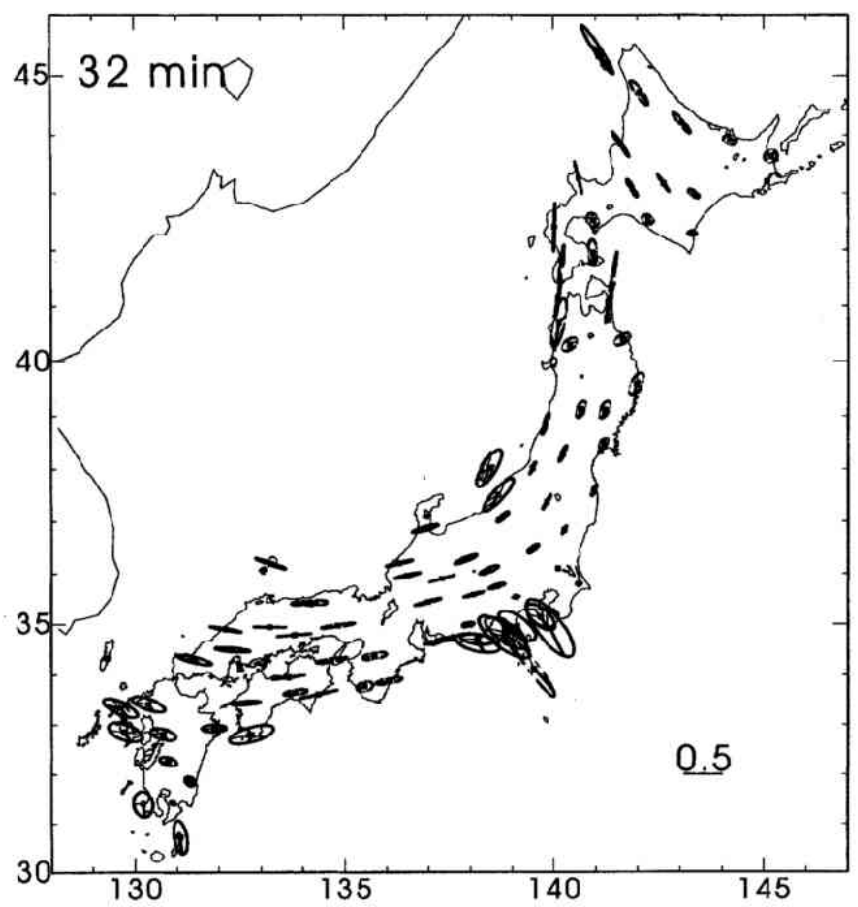

Fig. 10. Anomalous ellipses of the horizontal transfer functions of the thin-sheet model calculation (real part).

\subsection{Differences between the observed transfer functions and the thin-sheet model transfer functions}

In this study, we regarded the induction arrows and the horizontal transfer functions as "vectors", which can be treated linearly. However, this treatment is not strictly correct (Weaver and Agarwal, 1991) because anomalous geomagnetic fields made by several conductors are coupled mutually and not separable. Bapat et al. (1993) and Chamalaun and McKnight (1993) treated the induction arrows as true vectors and removed the sea water effect from the induction arrows by subtracting the model calculated induction arrows assuming that the mutual coupling is weak compared with the self-induction by a primary source field. In a similar manner, we can expect that the difference between the observed transfer functions and the thin-sheet model transfer functions shows the effect of removing the sea water.

Histograms of transfer functions of observations and residuals (the observation minus the model) at the period of $32 \mathrm{~min}$ are shown in Fig. 11. Although the mean values of observed $A, C$ and $F$ are more than 0.1 , those of the residuals are less than 0.1. The standard deviations of both $A$ and $B$ of the residuals are smaller than those observed. If the resistivity anomalies are randomly distributed and the thin-sheet model is able to reproduce the effect of sea water, then the mean of residuals would become 0 and the standard deviations would become small. However, the standard deviations of the horizontal transfer functions were not improved. This suggests that the effect of sea water on the horizontal transfer functions is less than that on the vertical transfer functions.

The residual induction arrows and anomalous ellipses, which are the difference between those of the observation and those of the thin-sheet model, are shown in Figs. 12 and 13, respectively. Residual induction arrows generally become smaller, except in some anomalous regions (e.g. southern Hokkaido District, Kanto District and southern Kyushu District), but the effect of the ocean on the anomalous ellipses is smaller. 
(a)

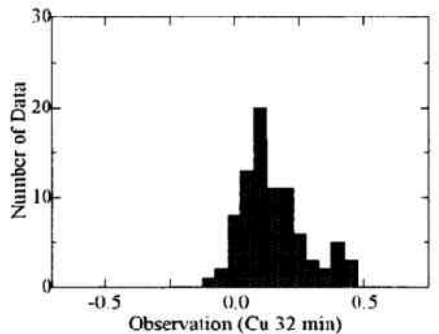

mean $=.1498 \mathrm{sd}=.1256$

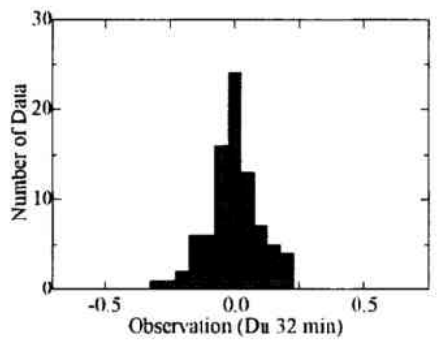

mean $=-.0038 \mathrm{sd}=.1002$

(b)

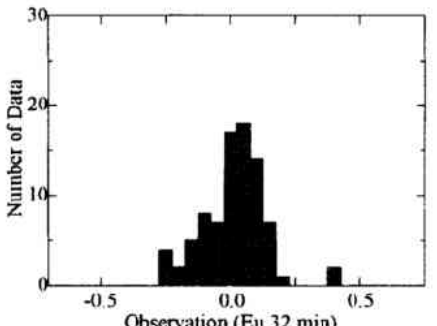

mean $=.0104$ sd $=.1219$

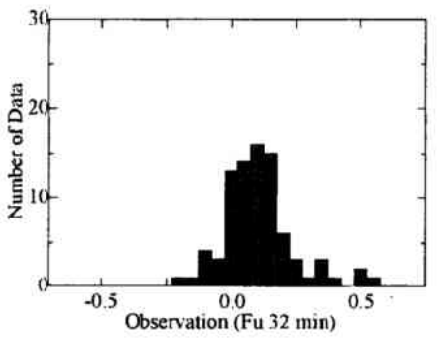

mean=.1158 $\mathrm{sd}=. \mathbf{1 5 5 6}$

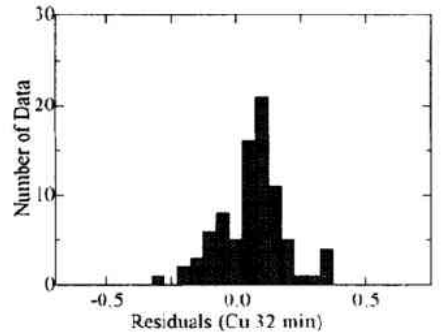

mean $=.0745$ sd $=.1590$

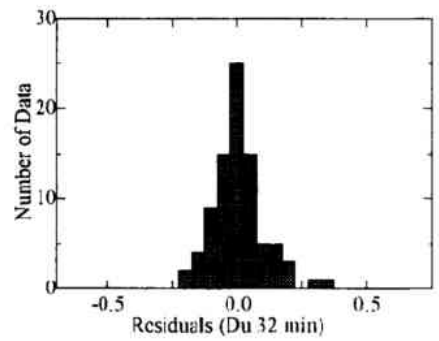

mean $=.0081 \mathrm{sd}=.0951$

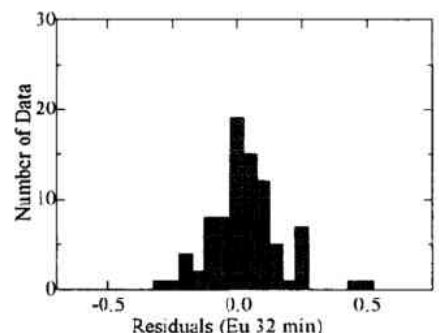

mean $=.0325$ sd $=.1333$

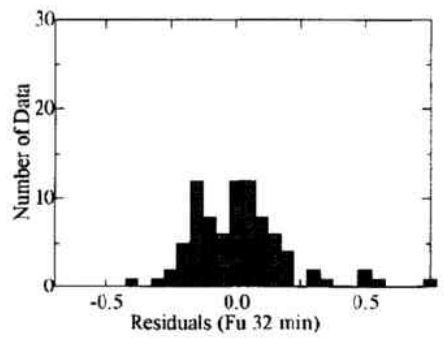

mean $=.0284 \mathrm{sd}=.2193$

Fig. 11. Histograms of the observed and the residual transfer functions. The real parts are donated with suffix $u$. 
(c)

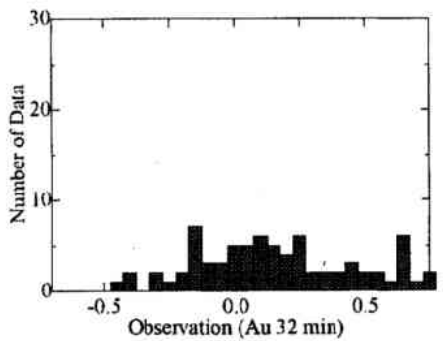

mean $=.1381 \mathrm{sd}=.4501$

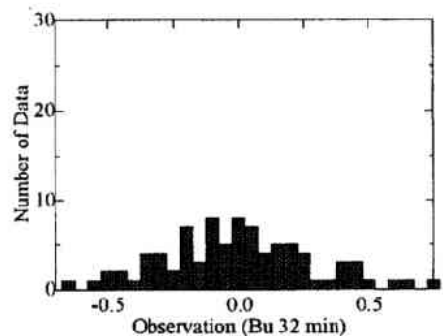

mean $=-.0055 \mathrm{sd}=.2825$

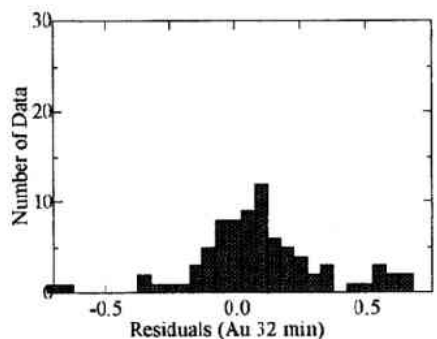

mean $=.0473$ sd $=.3248$

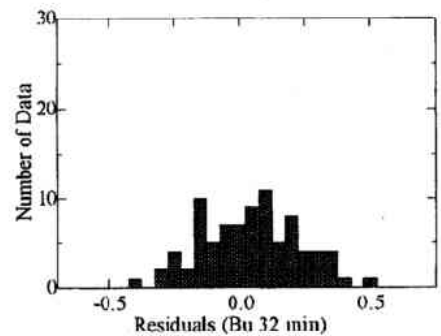

mean $=.0433$ sd $=.1854$

Fig. 11. (continued)

(a)

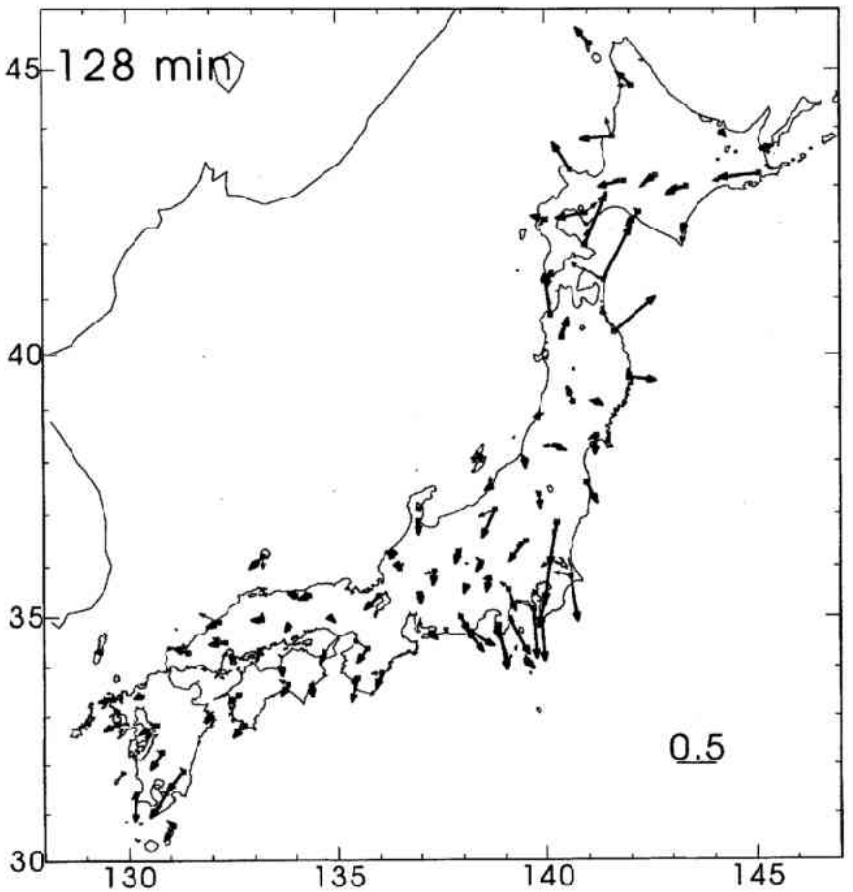

Fig. 12. Residual remote reference induction arrows. The thick line with a large arrowhead shows a real part and the thin line with a small arrowhead shows an imaginary part. 
(b)

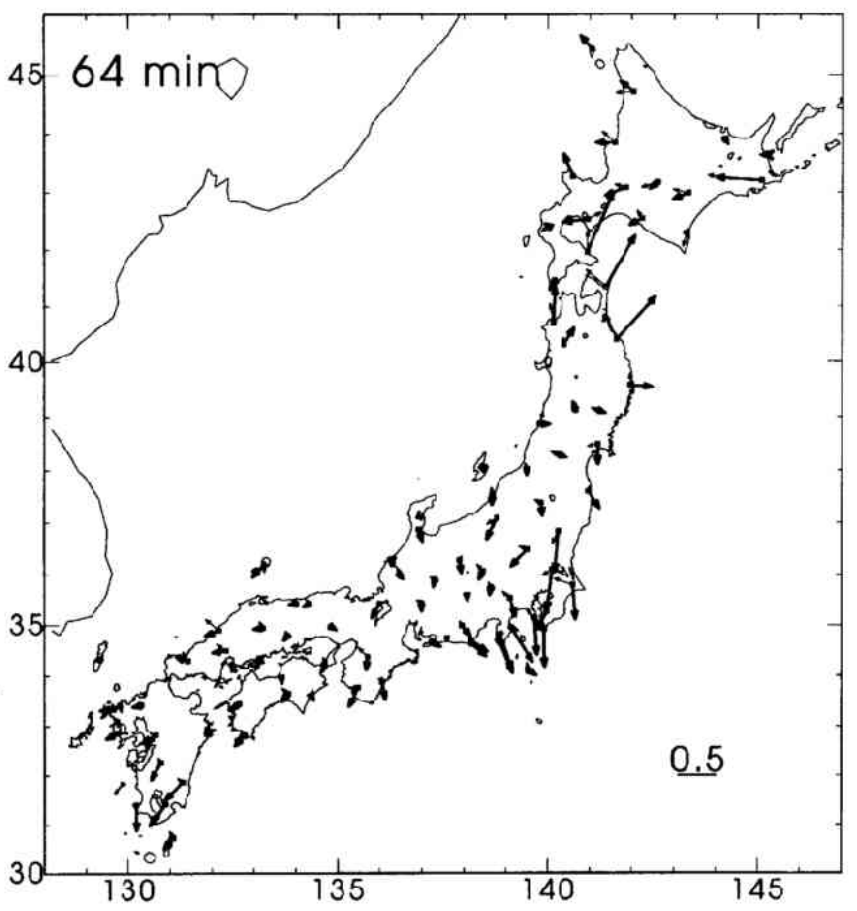

(c)

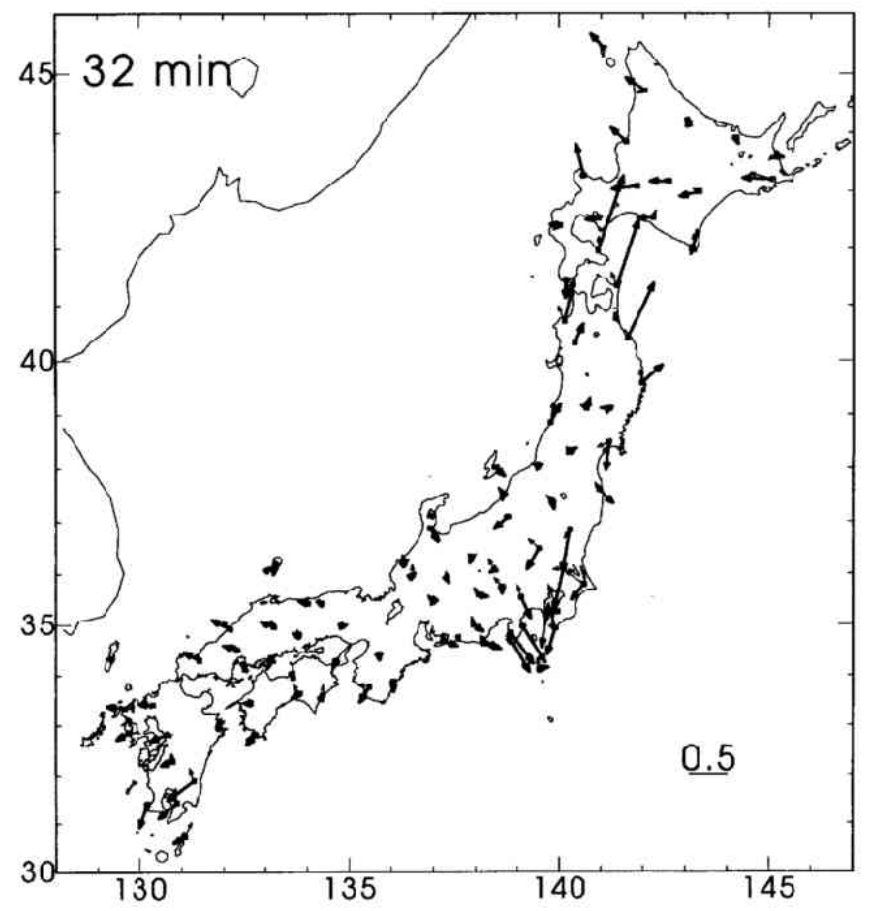

Fig. 12. (continued). 
(a)

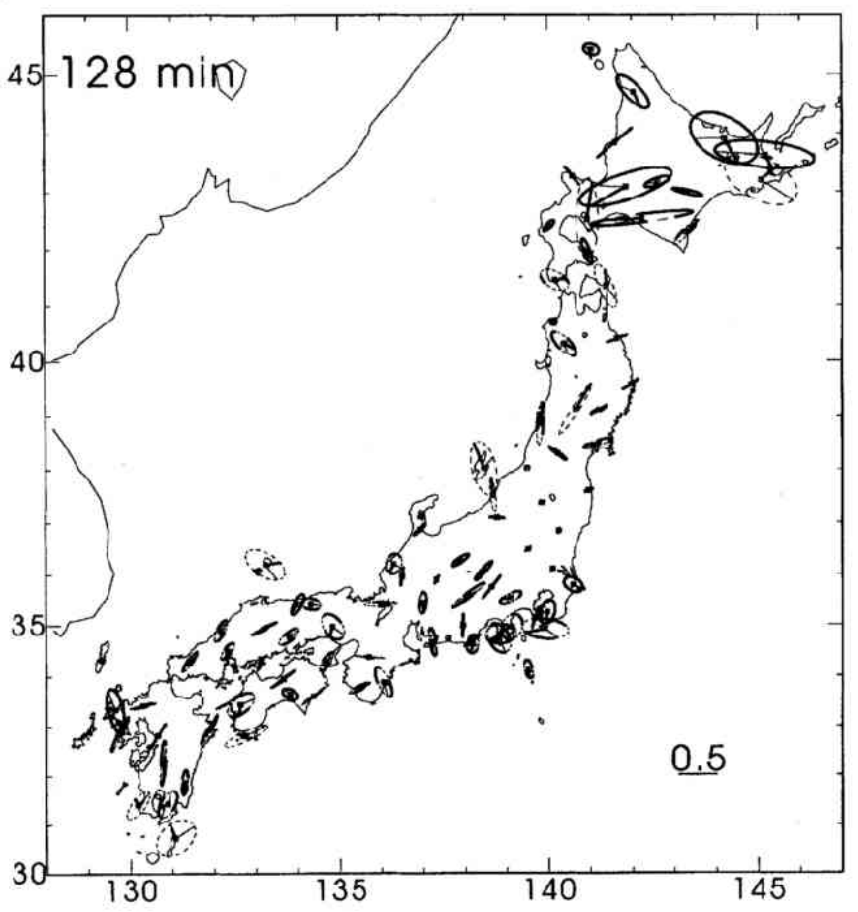

(b)

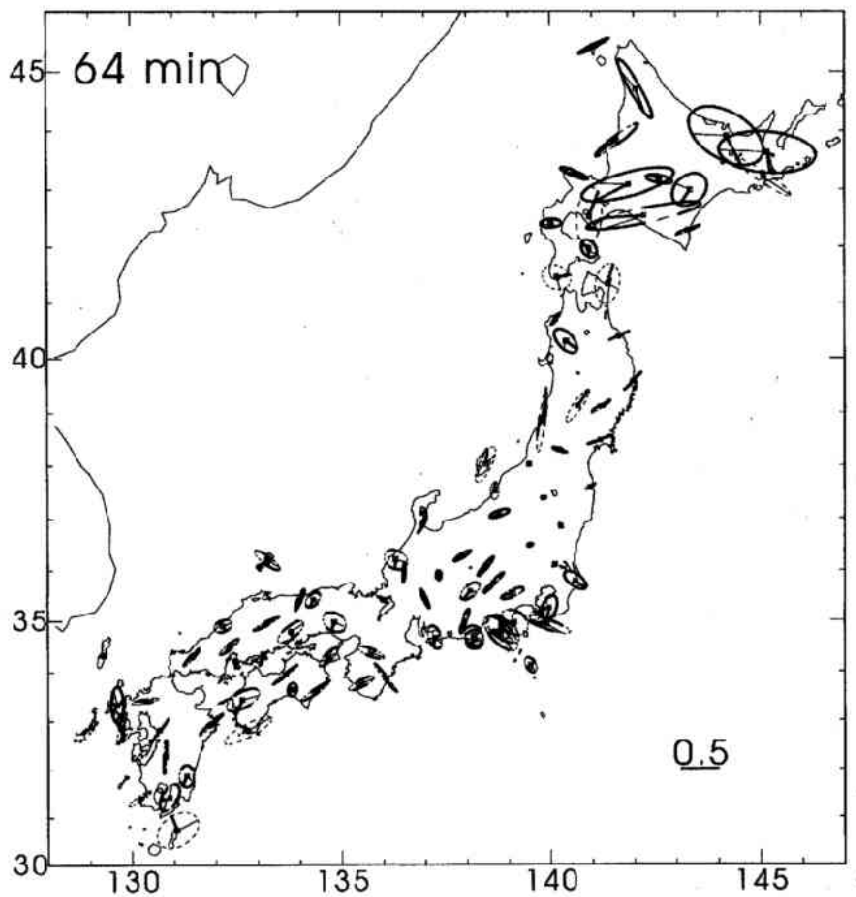

Fig. 13. Residual anomalous ellipses of the horizontal transfer functions (real part). 
(c)

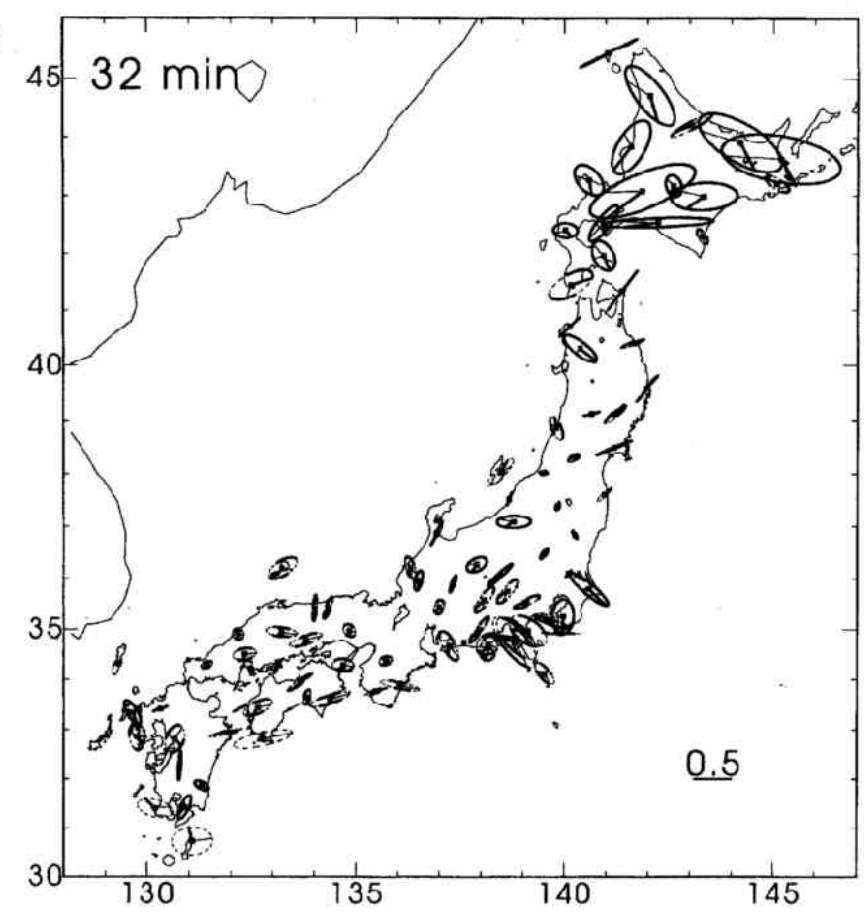

Fig. 13. (continued).

\section{Discussion}

\subsection{Induction arrows and anomalous horizontal field}

(a) Interpretation of induction arrows and anomalous horizontal field

Induction arrows are commonly used in Geomagnetic Depth Sounding (GDS) studies. The induction arrows indicate lateral variations in anomalous electric currents while the horizontal transfer functions represent anomalous currents beneath the station. The maximum of the anomalous horizontal field is located just above the induced current concentration. Although electric currents may be directly induced in low resistivity regions (good conductors), currents may also be channeled. Therefore we must pay attention to the current flow in addition to anomalous conductors themselves.

(b) Selection of the reference station

As discussed previously, the reference station should be a "normal" station, in the sense that it should be situated above horizontally stratified resistivity structure, and sufficiently distant from any lateral discontinuities (Banks, 1973). From this definition, the coherence between any pair of the components $\Delta X$, $\Delta Y$ and $\Delta Z$ should be zero. Since $\Delta X$ and $\Delta Z$ of KAK have high coherency, we did not use $\Delta Z$ of KAK in the remote-reference calculation.

We considered KAK as a suitable reference station for the following reasons. As the horizontal transfer functions in inland parts of Tohoku District are small (Fig. 7), we can assume that the horizontal fields measured at KAK are the same as that of the other stations in Tohoku District. In addition, we can not find systematic anomalies in northern and southern Japan where there are great distances from KAK. The high coherency of the horizontal components between KAK and other observatories (Table 2) also supports the selection as a reference station.

(c) Effects of sea water and sediments

A contribution to the anomalous magnetic field is provided by induced electric currents in sea water, 
known as the coast, island and peninsula effects. Such effects were estimated in this study using the thinsheet algorithm, although the effects of complex and small scale coast lines could not be modelled accurately and we are restricted to periods longer than $32 \mathrm{~min}$.

The coast effect arises due to concentration of induced currents in the ocean, which produces large anomalous vertical fields near the coast. Since coastlines often run parallel to tectonic structures, such as plate boundaries, we must pay attention to the interpretation of the coast effect.

The anomalous ellipses of the horizontal transfer functions in an island or a peninsula show frequency dependence that they become smaller at shorter periods. Especially at the island stations such as No. 85 Tanegashima and No. 87 Saigou and peninsula stations such as No. 47 Tanabe and No. 72 Nakamura, the horizontal transfer functions show large attenuation at shorter periods. This effect is similar to that observed by ocean bottom magnetometer studies (e.g. Filloux, 1967). Magnetic field variations at shorter periods are attenuated at the seafloor because sea water has low resistivity. The mechanism of the island and peninsula effect is different from that of the ocean bottom case. As electric currents tend to flow into sea water around an island or a peninsula and don't tend to flow just under the island or the peninsula, the horizontal magnetic field becomes smaller in the island or the peninsula, especially at shorter periods.

At No. 33 Ishinomaki, No. 34 Sakata, No. 42 Choushi and KNZ, the anomalous ellipses of the horizontal transfer function show large anisotropy at shorter periods associated with the Sendai plain, the Shonai plain and the Kanto plain, respectively. The shorter axes of the ellipses are parallel to the plains and perpendicular to the coast lines. Furthermore, at No. 34 Sakata the induction arrows at shorter periods than $32 \mathrm{~min}$ in Fig. 5 point to the north and this can be explained by the low resistivity sediments of the Shonai plain. They also show frequency dependence. These phenomena are probably explained by concentration of currents in the sediments from the ocean.

\subsection{Discussion with respect to the three districts}

Figure 14 shows topographic features in eastern Japan. Generally, regions below $100 \mathrm{~m}$ coincide with plains usually covered by low resistivity sedimentary layers.

(a) Hokkaido and Tohoku District

Hokkaido is situated at the junction of two island arcs, the Northeastern Japanese arc and the Kurile arc. Nishida $(1976,1977 \mathrm{a}, 1977 \mathrm{~b}, 1981,1982)$ studied the anomalies of geomagnetic variations in Hokkaido, and Kato (1968) found the northeastern Japan anomaly, which lies just south of Hokkaido. The northeastern Japan anomaly was interpreted in terms of a channeling of electric currents between the Pacific Ocean and the Japan Sea through the Tsugaru Strait (e.g. Rikitake and Honkura, 1985), although Avdeev et al. (1995) showed that induction arrows at $256 \mathrm{sec}$ period could not be fully explained only by the channeling.

Figure 12 shows that there are the large residual induction arrows that point to the northeast at the sites along the eastern coast of southern Hokkaido, No. 27 Shimokita and No. 28 Hachinohe in northeastern Japan (Tohoku District). Figure 13 shows that there are strong anomalous horizontal transfer functions along the Ishikari plain. The current that flows into and out of the Ishikari plain can produce large induction arrows and the horizontal transfer functions (Nishida, 1976, 1981).

Nishida (1982) concluded that a low resistivity layer exists at a depth range of 30 to $70 \mathrm{~km}$ beneath the inner part of the Volcanic Front of the northeastern Japanese arc. He also concluded that the effect of the low resistivity layer, situated at the west of the Ishikari plain, cancels the $\Delta Z$ component which occurs from the surface sediment layer. Although this conclusion seems to coincide with the observed horizontal transfer functions (Fig. 7), the residual horizontal transfer functions (Fig. 13) at the periods of 64 and 128 min of No. 18 , No. 23 , No. 25 , No. 26 and No. 80 in the southwestern Hokkaido are not so anomalous, except for the anomalies associated with the Ishikari plain. The residual induction arrows at No. 25 and No. 80 (Fig. 12) are small and the residual anomalous ellipses No. 26, No. 27, No. 80 and No. 81 (Fig. 13) show that the current along the Tsugaru Strait is small at longer periods. In this region, the depth of the Moho discontinuity is about $35 \mathrm{~km}$ and the plate boundary is deeper than $100 \mathrm{~km}$ (Miyamachi et al., 1993). In Tohoku and Chubu districts, low resistivity layers exist between the Conrad discontinuity and the Moho 


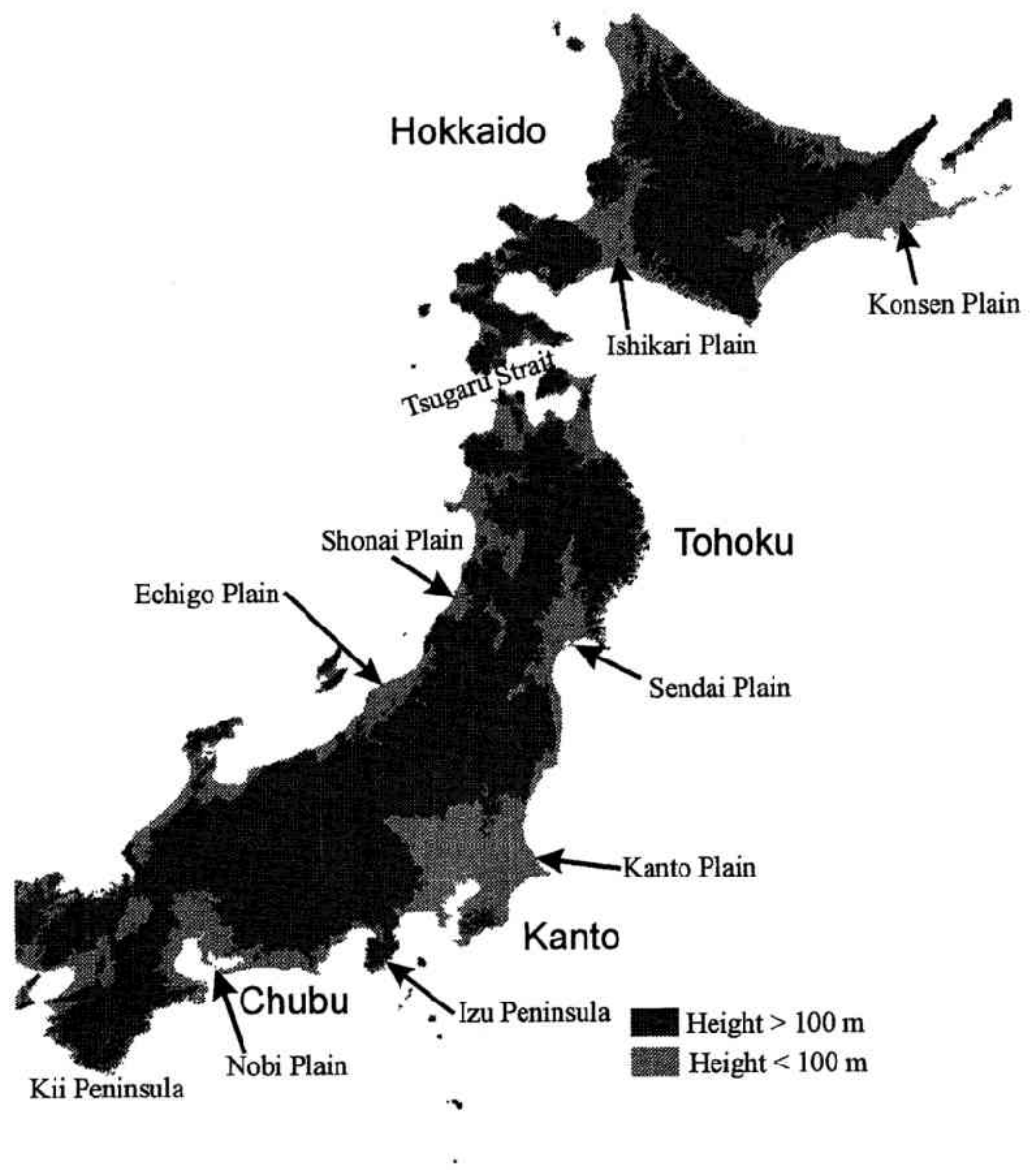

Fig. 14. Topographic features in eastern Japan.

discontinuity beneath around the Volcanic Front (e.g. Utada, 1987). Residual transfer functions are small and the effect of the low resistivity layer is not dominant at longer periods. Therefore, there is a possibility that the low resistivity layer exists at a depth shallower than the Moho discontinuity in southern Hokkaido.

Figure 13 shows that there are large anomalies of the horizontal transfer functions in northern and eastern Hokkaido. Nishida (1981) pointed out that this region is characterized by large horizontal fields which may be explained by the sediments of the Cenozoic group.

By contrast, in northeastern Japan, anomalies of the horizontal transfer functions are smaller. The Ishikari plain and the Konsen plain in Hokkaido are both adjacent to ocean and current channeling may occur through the sediments. Anomalies of the horizontal transfer functions in the northeastern Japan are small, as less current channeling occurs.

(b) Kanto and Chubu District

In the early 1950's, a significant variation of the vertical component was observed at KAK in northern Kanto District. It was the first study of the so-called central Japan anomaly (Rikitake, 1966). Honkura (1985) showed that this central Japan anomaly is primarily accounted for by surface sediments and sea water, although no significant information on the crustal and mantle resistivity structure could be derived. Bapat et al. (1993) also showed that the central Japan anomaly can be explained primarily by the sea effect 
and local anomalies of the sedimentary layer using a thin-sheet model. However, the distribution of geomagnetic stations in their study does not cover all Kanto District, particularly in and around the Izu peninsula. Yanagihara and Yokouchi (1965) and Honkura (1985) showed that there are large currents in the thick sediment in the Kanto plain. In the northern Kanto District, the large residual induction arrows at No. 40 Utsunomiya and TKB are accounted for by these currents.

Most anomalies in the northern Kanto District can be explained by the sediment layer and sea water effect. However, in the southern Kanto District and the Izu peninsula, there are large residual induction arrows that point to the south, far off the Izu peninsula. Although all the sea water effects can not be entirely removed due to the complicated coastlines the residual induction arrows are too large to be explained by the sediment and sea water effects alone. The Kanto District is divided into three tectonic plates (the Philippine Sea, Eurasian and Pacific plates) and two island arcs (the Izu-Ogasawara, which subducts beneath the other island arc, the Japan arc) (Ishida, 1992). At sea, the upper layer of the plates has low resistivity, which significantly affects the induction arrows (Utada, 1987). Figure 15 shows the plate boundary between the Philippine Sea plate and the Eurasian plate (Ishida, 1992). The residual induction arrows in the southern Kanto District point toward the Philippine Sea plate (Fig. 12). It follows that the effect of the Philippine Sea plate on the induction arrows is probably large in southern Kanto District.

The observed and residual induction arrows at No. 39 Tookamachi and No. 97 Tochigi point to the southwest. Induced electric currents in the sediment layer in the Kanto plain tends to flow parallel to the NW-SE trend of thick sediments (Yanagihara and Yokouchi, 1965). Therefore, these currents probably flow from the northern edge of the Kanto plain to the Japan Sea. Similarly, Fig. 7 shows that the regional general current flows in a NW-SE direction in Chubu inland District and is approximately uniform. This current flows between the Pacific Ocean and the Japan Sea through this region. From a 2D study of geomagnetic induction, Utada (1987) showed that there are low resistivity layers in the lower crust above the Moho discontinuity beneath and around the Volcanic Front, and the current flowing in the upper surface of the Philippine Sea plate probably flows into there. The NW-SE current in the Izu peninsula (Fig. 13 , just above the northern tip of the Philippine Sea plate) also supports this hypothesis. Figure 15 shows a schematic explanation of the electric currents in Kanto and Chubu District associated with the Philippine Sea plate.

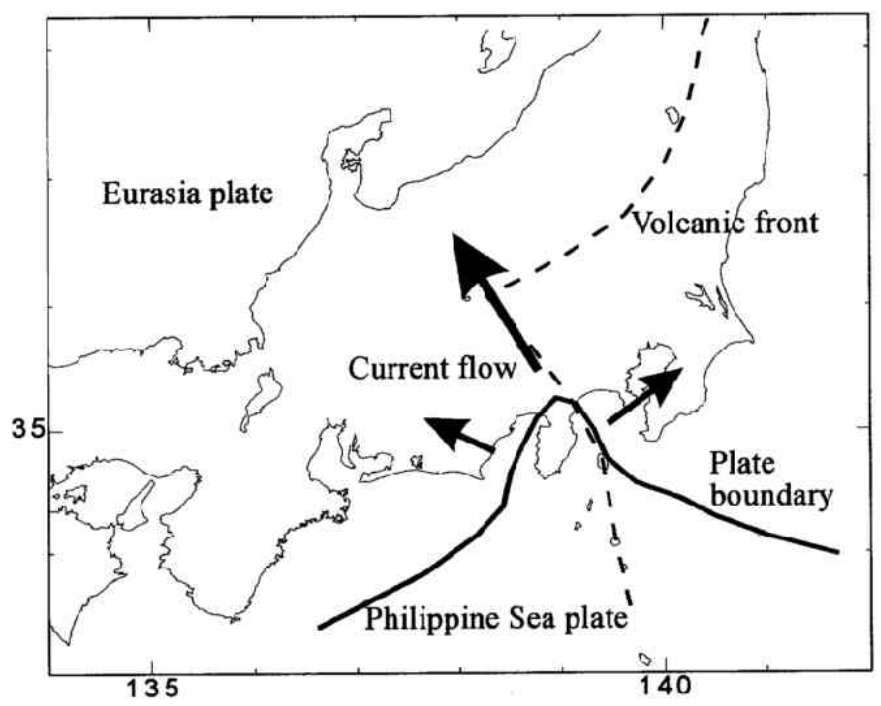

Fig. 15. Plate boundary of the Philippine Sea plate and the Eurasian plate (thick line), volcanic front (broken line) and schematic explanation of electric currents (arrows) in Kanto and Chubu District associated with the Philippine sea plate. 
On the other hand, the low resistivity layers of the Pacific plate east of the Kanto District can not be detected and their effect on the transfer functions should be small. This is because the Pacific plate subducts under the Philippine Sea plate and the large electric current concentrates in the Philippine Sea plate is nearer than that of the Pacific plate.

In the southern Kii peninsula, the residual induction arrows shown in Fig. 12 point to the south but they are small. However, Bapat et al. (1993) showed an opposite result that there are the large residual induction arrows in the southern Kii peninsula. Fujita (1994) concluded that low resistivity layer of 10 ohm'm exists below the Pacific ocean near the tip of the Kii peninsula, using MT and GDS methods. We cannot make a direct comparison with these conclusions because there are no first order geomagnetic stations at the tip of the Kii peninsula. However, it seems reasonable to suppose that low resistivity layer does not exist just below the Kii peninsula. This hypothesis is supported by the fact that the horizontal transfer functions are small in the southern Kii peninsula.

(c) Chugoku and Kyushu District

In Chugoku, northern and central Kyushu, most induction arrows point to the west (Research Group for Crustal Resistivity Structure, Japan, 1989; Handa et al., 1992) and the residual induction arrows (Fig. 12) also support this tendency. Handa et al. (1992) suggested that there are low resistivity layers beneath the Yellow Sea (to the west of Kyushu) and that current channeling occurs, possibly in the Tsushima strait (to the north of Kyushu). It is interesting that the residual induction arrows in southern Kyushu point to the southwest and they are larger than those of northern and central Kyushu (Fig. 12). Although the station No. 85 Tanegashima is situated in northeastern part of Tanegashima island, induction arrows do not show the island effect at longer periods and point to the south. Moreover, the anomalous ellipses of the horizontal transfer functions in Kyushu suggest that there are East-West currents. Therefore, such EastWest currents in southern Kyushu and southern off Kyushu most probably produce the anomalies of the transfer functions in southern Kyushu.

\section{Concluding Remarks}

We have determined a nation wide distribution of geomagnetic transfer functions around Japan, for both the vertical field and the horizontal field, using the interstation method. We also estimated the effect of sea water using the thin-sheet method. As the coastlines of Japan are complex, the model calculation could be improved by using a finer mesh or by considering a smaller area. However, the residual transfer functions show large anomalies that can not be explained by the effect of the coastlines alone. Current channeling in sedimentary layers may account for some of the observed anomalies. The large anomaly in southern Kanto District is most likely related to the existence of the Philippine Sea plate.

We wish to thank all the members of Geomagnetic section of the Geographical Survey Institute who made efforts to get data of the geomagnetic stations. We thank Kakioka Magnetic Observatory, the Japan Meteorological Agency, for providing MMB, KAK, KNY, OMZ and MTZ data. We also thank Yatsugatake Magnetic Observatory, the Earthquake Research Institute, the University of Tokyo, for providing YAT data. We are grateful to Dr. Graham S. Heinson for reading the manuscript and making a number of helpful suggestions.

\section{REFERENCES}

Agarwal, A. K. and J. T. Weaver, Regional electromagnetic induction around the Indian peninsula and Sri Lanka; a threedimensional numerical model study using the thin sheet approximation, Phys. Earth Planet. Inter., 54, 320-331, 1989.

Avdeev, D. B., Y. Ogawa, A. V. Kuvshinov, and O. V. Pankratov, An interpretation of magnetovariational data in the northern Tohoku District, Japan, using multi sheet modelling, J. Geomag. Geoelectr., 47, 405-410, 1995.

Banks, R. J., Data processing and interpretation in geomagnetic deep sounding, Phys. Earth Planet. Inter., 7, 339-348, 1973.

Bapat, V. J., J. Segawa, Y. Honkura, and P. Tarits, Numerical estimation of the sea effect on the distribution of induction arrows in the Japanese island arc, Phys. Earth Planet. Inter., 81, 215-229, 1993.

Beamish, D., A geomagnetic precursor to the 1979 Carlisle earthquake, Geophys. J. R. astr. Soc., 68, 531-543, 1982. 
Bendat, J. S. and A. G. Piersol, Random Data: Analysis and Measurements, 407 pp., Wiley-Interscience, New York, 1971.

Camfield, P. A. and D. I. Gough, Anomalies in daily variation magnetic fields and structure under north-western United States and south-western Canada, Geophys. J. R. astr. Soc., 41, 193-218, 1975.

Chamalaun, F. H. and J. D. McKnight, A New Zealand wide magnetometer array study, J. Geomag. Geoelectr., 45, 741-759, 1993.

Everett, J. E. and R. D. Hyndman, Geomagnetic variations and electrical conductivity structure in south-western Australia, Phys. Earth Planet. Inter., 1, 24-34, 1967.

Filloux, J. H., An ocean bottom, D-component magnetometer, Geophysics, 32, 978--987, 1967.

Filloux, J. H., Magnetotelluric soundings over the northeast Pacific may reveal spatial dependence of depth and conductance of the asthenosphere, Earth Planet. Sci. Lett., 46, 244-252, 1980.

Fujita, K., The study of the electrical resistivity structure beneath the Kii-peninsula using the electromagnetic method, Ph.D. Thesis, 121 pp., Kobe University, 1994.

Fujita, S., Monitoring of time change of conductivity anomaly transfer functions at Japanese magnetic observatory network, Mem. Kakioka Mag. Obs., 23, 53-87, 1989.

Gamble, T. D., W. M. Goubau, and J. Clarke, Magnetotellurics with a remote magnetic reference, Geophysics, 44, 53-68, 1979.

Geographical Survey Institute, First order geomagnetic survey in Japan from 1949 to 1994, Technical Rep. Geograph. Surv. Inst., B4-12, 174 pp., 1995.

Handa, S., Y. Tanaka, and A. Suzuki, The electrical high conductivity layer beneath the northern Okinawa trough, inferred from geomagnetic depth sounding in northern and central Kyushu, Japan, J. Geomag. Geoelectr., 44, 505-520, 1992.

Honkura, Y., Perturbation of induced electric currents by surface conductivity inhomogeneity with special reference to anomalous behavior of short-period geomagnetic variations in the Kanto Plain, J. Geomag. Geoelectr., 37, 627-641, 1985.

Ishida, M., Geometry and relative motion of the Philippine Sea plate and Pacific plate beneath the Kanto-Tokai district, Japan, J. Geophys. Res., 97(B1), 489-513, 1992.

Kato, Y., Northeastern Japan anomaly of the upper mantle, Proc. Conductivity Anomaly Symposium, 19-31, 1968 (in Japanese).

Lilley, F. E. M., Analysis of the geomagnetic induction tensor, Phys. Earth Planet. Inter., 8, 301-316, 1974.

McKirdy, D. McA., J. T. Weaver, and T. W. Dawson, Induction in a thin sheet of variable conductance at the surface of a stratified earth;-II. Three-dimensional theory, Geophys. J. R. astr. Soc., 80, 177-194, 1985.

Miyamachi, H., M. Kasahara, S. Suzuki, H. Okada, K. Tanaka, and A. Hasegawa, Three-dimensional velocity structure beneath northern Japan, Abstracts 1993 Fall Meeting of the Seismological Soc. Japan, p. 335, 1993 (in Japanese).

Nishida, Y., Conductivity anomalies in the southern half of Hokkaido, Japan, J. Geomag. Geoelectr., 28, 375-394, 1976.

Nishida, Y., Conductivity anomalies in and around the Ishikari Plain, Hokkaido, Geophys. Bull. Hokkaido Univ., 36, 17-28, 1977a (in Japanese with English abstract).

Nishida, Y., Observations of geomagnetic and gecelectric variations along the north-south profile of Hokkaido, Geophys. Bull. Hokkaido Univ., 36, 29-40, $1977 \mathrm{~b}$ (in Japanese with English abstract).

Nishida, Y., Anomalous behavior in the horizontal components of geomagnetic variations in Hokkaido, Japan, J. Geomag. Geoelectr., 33, 197-204, 1981.

Nishida, Y., Conductivity structure in and around Hokkaido, Japan as revealed by the period dependence of the CA transfer functions, J. Geomag. Geoelectr., 34, 453-465, 1982.

Otaki, M. and K. Tsukahara, Geomagnetic survey with the triaxial fluxgate magnetometer, Bull. Geograph. Surv. Inst., 35, 19, 1990.

Research Group for Crustal Resistivity Structure, Japan, The crustal resistivity structure in the Chugoku District, Japan (preliminary report), Proc. Conductivity Anomaly Symposium, 49-54, 1989 (in Japanese).

Rikitake, T., Electromagnetism and the Earth's Interior, 308 pp., Elsevier, Amsterdam, 1966.

Rikitake, T., The undulation of an electrically conductive layer beneath the islands of Japan, Tectonophysics, 7, 257-264, 1969.

Rikitake, T. and Y. Honkura, Solid Earth Geomagnetism, 384 pp., Terra Scientific Publishing Company, Tokyo, Japan, 1985.

Sano, Y., K. Nakaya, T. Kurihara, and S. Nakajima, Simultaneous comparisons of CA transfer functions among Memanbetsu, Iwaki, Kakioka and Kanoya, Mem. Kakioka Mag. Obs., 19, 53-68, 1982 (in Japanese with English abstract).

Schmucker, U., Anomalies of geomagnetic variations in the southwestern United States, Bull. Scripps Inst. Oceanogr., 13, 165 pp., 1970.

Shiraki, M., Monitoring of the time change in transfer functions in the central Japan conductivity anomaly, J. Geomag. Geoelectr., 32, 637-648, 1980.

Utada, H., A direct inversion method for two-dimensional modelling in the geomagnetic induction problem, Ph.D. Thesis, 409 pp., University of Tokyo, 1987.

Vasseur, G. and P. Weidelt, Bimodal electromagnetic induction in non-uniform thin sheets with an application to the northern Pyrenean induction anomaly, Geophys. J. R. astr. Soc., 51, 669-690, 1977.

Weaver, J. T. and A. K. Agarwal, Is addition of induction vectors meaningful?, Phys. Earth Planet. Inter., 65, $267-275,1991$.

Yanagihara, K. and T. Yokouchi, Local anomaly of earth-currents and earth-resistivity, Mem. Kakioka Mag. Obs., 12, 105-113, 1965 (in Japanese with English abstract). 